\title{
Music Perception and Octave Generalization in Rhesus Monkeys
}

\author{
Anthony A. Wright and Jacquelyne J. Rivera \\ University of Texas Medical School at Houston
}

\author{
Stewart H. Hulse \\ Johns Hopkins University \\ Julie J. Neiworth \\ Carleton College
}

Melissa Shyan

Butler University

\begin{abstract}
Two rhesus monkeys were tested for octave generalization in 8 experiments by transposing 6- and 7-note musical passages by an octave and requiring same or different judgments. The monkeys showed no octave generalization to random-synthetic melodies, atonal melodies, or individual notes. They did show complete octave generalization to childhood songs (e.g., "Happy Birthday") and tonal melodies (from a tonality algorithm). Octave generalization was equally strong for 2-octave transpositions but not for 0.5 or 1.5-octave transpositions of childhood songs. These results combine to show that tonal melodies form musical gestalts for monkeys, as they do for humans, and retain their identity when transposed with whole octaves so that chroma (key) is preserved. This conclusion implicates similar transduction, storage, processing, and relational memory of musical passages in monkeys and humans and has implications for nature-nurture origins of music perception.
\end{abstract}

Music is considered among cultures' highest achievements. Nevertheless, music from different cultures shares many characteristics. Among these common characteristics is that all music uses a limited number of possible notes. A limited number of possible notes helps to make songs memorable and reproducible. Other factors contribute to their memorability, reproducibility, and general appeal. Take, for example, the familiar tune "Happy Birthday." There is no doubt about its memorability. The first four notes readily identify it. Furthermore, different sets of four notes separated by whole octaves suffice equally well to identify "Happy Birthday."

Preverbal infants as well as adults can identify a transposed melody as the same melody while at the same time recognizing that the notes are different, that is, different pitch heights (e.g., Demany \& Armand, 1984; Pick \& Palmer, 1993, p. 199; Trehub, Morrongiello, \& Thorpe, 1985). Thus, the melody becomes a whole or gestalt unto itself, somewhat independent of the notes used to produce it.

Anthony A. Wright and Jacquelyne J. Rivera, Department of Neurobiology and Anatomy, University of Texas Medical School at Houston; Stewart H. Hulse, Department of Psychology, Johns Hopkins University; Melissa Shyan, Department of Psychology, Butler University; Julie J. Neiworth, Department of Psychology, Carleton College.

This research was partially supported by National Institutes of Health Grants MH-35202 and DA-10715 and National Science Foundation Grant IBN 9317868.

We gratefully acknowledge the assistance of Annie Takeuchi in analysis of the childhood song and synthetic melodies and supplying the tonal and atonal melodies for Experiments 7 and 8. We also thank Jim Bartlett and Jeffrey Katz for their careful and thoughtful suggestions on earlier drafts of this article.

Correspondence concerning this article should be addressed to Anthony A. Wright, University of Texas Medical School at Houston, Department of Neurobiology and Anatomy, PO Box 20708, Houston, Texas 77225. Electronic mail may be sent to anthony.a.wright@uth.tmc.edu.
Among critical variables in the recognition of melodies are contour (the pattern of up and down changes in pitch), interval (sequence of pitch distances in semitones), and chroma (key; e.g., Dowling \& Hollombe, 1977). All three of these variables contribute to melody perception and can change it in complex ways. When all three variables are controlled, there is almost no decrement in melody identification, even novel melodies (e.g., Massaro, Kallam, \& Kelly, 1980). For example, a 2-octave change in the melody where a starting note of $\mathrm{C}$ at $262 \mathrm{~Hz}$ is changed to a $\mathrm{C}$ at $1,048 \mathrm{~Hz}$ preserves the original melody almost perfectly. The importance of this "octave" effect can be demonstrated by comparing changes that are other than whole octaves. For example, changing the starting note (and melody) from a C at $262 \mathrm{~Hz}$ to an $F^{*}$ at $370 \mathrm{~Hz}$ is a much smaller frequency change. However, this much smaller frequency change has a much greater effect on changing the melody from its original. The octave scale is based on frequency doubling and is fundamental to music perception and the auditory system generally (e.g., Dowling \& Harwood, 1986). This special status of the similarity of octave-transposed notes can be modeled as a three-dimensional helix of ascending pitch where notes of the same key (e.g., C) are vertically aligned and are thus in close proximity (Shepard, 1982). In the present article, tests with frequencies doubled, halved, or higher multiples of two are referred to as octave-generalization tests.

Octave generalization is a special case of contour transposition, where, in addition to contour, intervals (sequence of pitch distances) and chroma are also preserved. An octave-generalized melody can sound so similar to the original, particularly after a time delay, that the change may not even be noticed. This is not to say that notes of the same key from different octaves are indistinguishable. Not only is the pitch change noticeable when melodies from different octaves are played in rapid succession, but (random) note substitutions from different octaves destroy the melody (Deutsch, 1972; Dowling \& Hollombe, 1977). Thus, a melody can be shifted all over the music scale and still retain its gestalt 
(melody) qualities. But substitutions from different octaves, even notes with the same letter name (same chroma), tend to destroy the gestalt.

The purpose of the studies presented in this article was to explore the possibility that some animal species might perceive music in the same gestalt-preserving way that humans do. When these studies began, there was little encouragement to be found for this possibility. Most human researchers have tended to regard music perception as a human experience. The small amount of animal research on this topic has done little to dispel this notion. Monkeys failed octave-generalization tests (e.g., D'Amato, 1988; D'Amato \& Salmon, 1984), and so did songbirds (e.g., Cynx, 1993; Dooling, Brown, Park, Okanoya, \& Soli, 1987; Hulse \& Cynx, 1985, 1986). In a review, D'Amato (1988) concluded that "monkeys can't hum a tune ... Because they don't hear them" (p. 478). And this deficiency "may be widespread among animals" (p. 453).

Furthermore, two widely referenced claims of octave generalization in animals do not stand scientific scrutiny. A claim of octave generalization in the white rat was based on one point for one test frequency displaced from one generalization gradient for one training frequency (Blackwell \& Schlosberg, 1943). Many more tests with other training and test frequencies would be necessary for this to be a definitive test of octave generalization today. A claim was made for octave generalization in the bottlenosed dolphin (Ralston, Herman, Williams, Gory, \& Jerger, 1988). It is difficult to tell the basis for this claim because it appeared only as a meeting abstract. This laboratory had previously shown that dolphins would spontaneously mimic computer generated sounds and would occasionally transpose their mimics by an octave (Richards, Wolz, \& Herman, 1984). It is unclear how these two references are related without more information. Experimental control of such spontaneous octave shifts undoubtedly would be difficult, and maybe this is the reason why these intriguing preliminary results were not followed up. In any case, when the research of this article began, there were several failures, few positive indications, and no definitive evidence in support of octave generalization in nonhuman animals.

Dauntless, we reasoned that contour and octave generalization should depend on relating two musical passages. Relational learning, in this case, means that the subject relates the two musical passages and has learned the same-different concept. Concept learning is assessed by testing with novel stimuli. If the concept has been learned, then accurate same-different judgments should be made to any pair of sounds or music, whether they be familiar or novel. Furthermore, training and testing should be conducted in a musical context. A musical context means that judgments should be based on a sequence of notes, that is, a melody, not individual notes or sine-wave tones. Simply training with melodies instead of notes does not always ensure that judgments will be based on the whole melody. Individual notes of a melody can come to control the behavior. Such a result becomes most likely when only a few melodies are used in training and when absolute identification of a particular melody is required (e.g., go/no-go tasks) rather than a relationship between melodies. Go/no-go tasks typically have a single $\mathrm{S}+$ stimulus in which responses are rewarded. In a study by D'Amato and Salmon (1984), for example, only certain notes, not the whole tune, were shown to control the go/no-go discrimination of monkeys.
With these requirements of relational concept learning and a musical context, two relations emerge. The first relation is among the notes-the melody. The other relation is between melodiesthe same-different judgment. Therefore, the task might be thought of as a relation between relations or analogical-reasoning task (e.g., Gillan, Premack, \& Woodruff, 1981). Unfortunately for the prognosis of these experiments, only language-trained chimpanzees and humans are thought capable of learning analogicalreasoning tasks (Premack, 1983a, 1983b). Such a task might become simplified if the notes configure together as gestaits (melodies). Simplifying the analogical-reasoning task by resolving the relationship among notes into a gestalt (melody) might allow species less sophisticated than language-trained chimpanzees to learn such a task.

For a variety of reasons, rhesus monkeys were used in these studies, not the least of which was that rhesus monkeys learn relationships among visual stimuli more readily than do some other species such as pigeons (Wright, Cook, \& Kendrick, 1989; Wright, Santiago, Sands, \& Urcuioli, 1984). Despite their relative predisposition for learning visual relationships, researchers had not had much success in training rhesus monkeys in auditory relational tasks (Mishkin, personal communication; Thompson, 1980). Nevertheless, after several task modifications, including the requirement that monkeys touch the speakers (sound sources), two rhesus monkeys eventually did learn an auditory same-different task.

In this auditory same-different task, the sample (first) sound was presented from a center speaker. A second sound was then presented simultaneously from two side speakers. If this second sound matched the first sound, then a touch to the right-hand speaker was required to obtain reward. If the second sound was different from the first sound, then a touch to the left-hand speaker was required to obtain reward. A fading procedure was used in the early training stages of this task. Initially, the second sound came only from the correct side speaker. The intensity of second sound from the incorrect side speaker was gradually increased in intensity until both speakers were equal. Natural (e.g., coyote howl) and environmental (e.g., car crash) sounds were used in the original training and testing and in maintaining accurate performance on this task in the experiments of this article.

The monkeys' relational learning in this same-different task was shown by their abstract concept learning; they performed as well with novel stimuli as with training stimuli (Wright, Shyan, \& Jitsumori, 1990). The experiments presented in this article capitalized on the monkeys' auditory same-different concept learning as the basis for testing music perception and octave generalization. The order in which the experiments are presented is the order in which they were conducted.

\section{Experiment 1}

The purpose of Experiment 1 was to test contour transpositions of "synthetic" melodies in a same-different task with monkeys. These melodies were essentially a random collection of notes within a restricted frequency range. Music training began by gradually introducing music trials while maintaining accurate performance with natural/environmental sound stimuli. Stable performance with natural sounds assured a stable baseline and maintained the same-different concept. As was done in training with natural sounds, melody training was conducted with a large num- 
ber of synthetic melodies played by different musical instruments. Large numbers of stimuli, which continuously vary, promote relational learning and concept learning (e.g., Homa, Cross, Cornell, Goldman, \& Shwartz, 1973; Homa \& Vosburgh, 1976; Wright, Cook, Rivera, Sands, \& Delius, 1988).

\section{Method}

\section{Subjects}

The subjects were two male thesus monkeys (Macaca mulatta). BW was 12 years old and FD was 13 years old at the beginning of the experiment. The monkeys had extensive training with natural/environmental sounds prior to these experiments (Wright et al., 1990).

The monkeys were maintained in state and federally approved facilities. Both monkeys were given ample access to food and water approximately 2 hours after their experimental sessions. Testing was conducted 5-6 days per week. On days when they did not participate in experimental sessions, they were given unrestricted access to food and water, and their diet was supplemented with fresh fruit.

\section{Apparatus}

A schematic of the apparatus is shown in Figure 1. A monkey cage was modified, including removing a bar from each of three walls. Speakers were positioned outside the cage where the bars had been removed. The monkeys touched copper screens in front of each speaker. A computer monitored touches (via high-impedance CMOS circuits), controlled sessions, collected data, and sequenced stimuli. The stimuli themselves were digitized and stored in a second computer (see Wright et al., 1990, for additional details).

Banana pellets ( 1 gram) were dispensed into a cup inside the cage below the center speaker. Tang orange drink $(3.5 \mathrm{cc}$ ) was dispensed adjacent to the side speakers, on the right side of the right speaker and on the left side of the left speaker.

\section{Procedure}

On each trial, a flashing light (dim green LED with a white plastic alligator-clip cover) behind the center-speaker copper screen indicated that a trial could begin. A touch to the center speaker (copper screen) produced a banana pellet and began playing the first sound or sample. Most trials contained natural or environmental sounds like those used in the original training and concept testing of the monkeys. On several trials in the experiments reported in this article music stimuli were presented for training or testing. The stimuli are described more thoroughly in the next section. Both stimuli on a trial were either natural/environmental stimuli or music stimuli, never a mixture of the two types.

The sample sound was played for $3 \mathrm{~s}$ from the center speaker. Following the sample, there was a 1-s delay and then a second or test sound was played. The test sound was played simultaneously from both side speakers for 2-6 s. Choice responses were accepted after $2 \mathrm{~s}$ of the second sound. The test sound was a repeat of the sample sound on half the trials, and the monkey was required to touch the right-side speaker to obtain juice reward. On the other half of the trials, there were two different sounds. On these trials, the test sound did not match the sample, and the monkey was required to touch the left-side speaker to obtain juice reward. A sidespeaker (choice) response within the 2-6-s response interval terminated the test sound. Incorrect choices or aborts (not responding within the 2-6-s interval of test sound) were not rewarded and were followed by a 30-s time-out. A 12-s intertrial interval followed correct choices or time-outs. There was no correction procedure (e.g., repetition of incorrect trials).

There were 30 trials in a daily session and 15 daily sessions in the experiment. In a daily session, there were 24 training trials with natural/
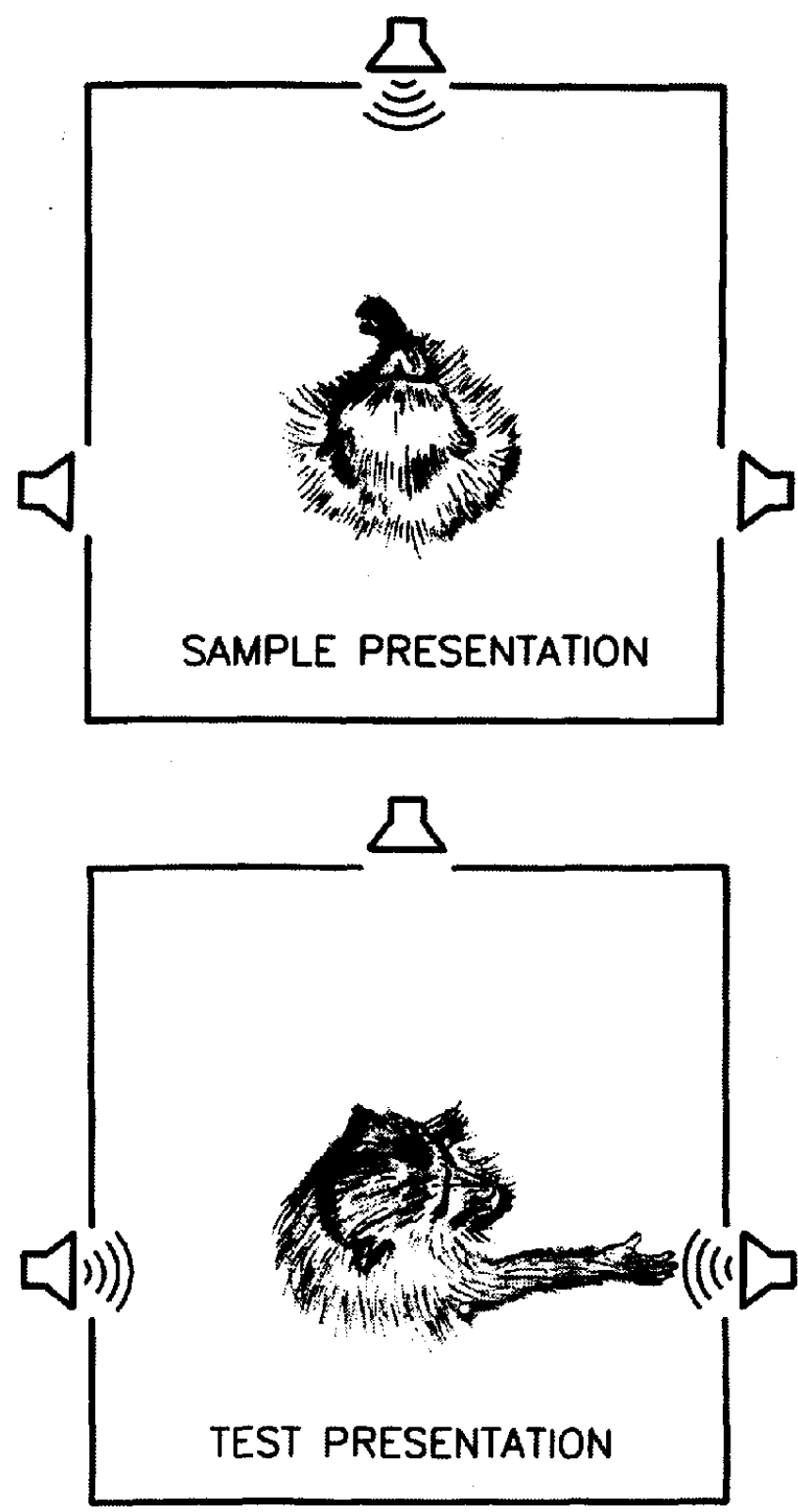

Figure 1. Schematic of test procedure. Upper panel shows top view of a monkey with sample sound being presented from a center speaker. Lower panel shows top view of a monkey touching a right side speaker with a test sound being presented from both side speakers. A touch to the right side-speaker was correct when the test sound matched the sample sound, and to the left when it did not match the sample sound.

environmental sounds, two training trials with melodies, and four test trials with melodies. For the two training trials with melodies, one was a same trial where the same melody with the same frequencies was repeated and a same response was rewarded. The other melody training trial was a different trial where different melodies with different frequencies were presented, and a different response was rewarded. In other words, on same trials the contours, intervals, and frequencies of the two melodies were identical, whereas on different trials the contours, intervals, and frequencies were different. The melodies were selected quasirandomly daily and were counterbalanced within the limits of the experiment. 
The four melody test trials differed from the two melody training trials in that either the melody or frequency was different between the two musical passages on a trial. On two test trials, the melody was the same but the frequency was different. These trials are referred to as Same-Melody, Different-Frequency (SAME-TUNE DIFF-FREQ) and are the transposition tests of primary interest in this experiment.

On the other two test trials, the melodies were different but the frequencies were the same. These trials are referred to as Different-Melody, Same-Frequency (DIFF-TUNE SAME-FREQ) trials. These test trials are control tests for frequency differences, as opposed to melody differences. In this experiment, the two melodies were the same six notes scrambled so that the order of notes in the two musical passages was different on these trials.

Test trials in these experiments were perceptual tests. Therefore, no particular response could be defined as correct and rewarded without "training" the behavior to be tested. Thus, on these test trials either response was rewarded. The alternative would have been to reward no response (extinction). The problem with extinction is that monkeys will learn that test trials are a cue for extinction, and performance on these trials will deteriorate. By rewarding either response, it is more likely that the subject's initial response tendencies will continue to be maintained.

Stimuli. There were 520 natural/environmental sounds (Elektra Records, NY, NY) used in these experiments (e.g., boat whistle, jack hammer, dive klaxon, owl hoots, turkey gobbles, pig grunts, fire alarm, baby crying, woman laughs, cable car, squeaky door, busy signal, dentist drill, bell buoy, sonar pings, stagecoach passing, water pouring, fog hom, man snoring, anchor chain, ping pong, coyote howls, etc.). From the $\mathbf{5 2 0}$ pool of natural/environmental sounds, 36 sounds were used daily, and each sound was presented on only one trial (trial unique). Representation of any individual sound was separated by several days of testing. Pairing of sounds, sequences of same-different trials, and placement of test trials varied quasirandomly from day to day.

The random-synthetic melodies were six note sequences generated from a computer linked to a Yamaha DX7 synthesizer. Notes and internote intervals were $80 \mathrm{~ms}$. Melodies were repeated (with a 500 -ms separation) to provide appropriate sample and test stimulus durations. The test duration (side speakers) depended on when in the 2-6-s response time the subject made its choice response. Each melody used in the experiment was recorded by 10 different keyboard instruments (Flute, Accordion, Spanish
Guitar, Oboe, Electric Piano, Bag Pipe, Clarinet, Grand Piano, HonkyTonk Piano, and Glockenspiel). All notes of a melody and both melodies of a trial were played by the same instrument. The six notes of each melody were quasirandomly selected with the restriction that they be located within a 12-semitone range. There were 48 possible semitones that the notes could represent, covering a four-octave range from $131 \mathrm{~Hz}$ (C) to 1,976 (B) $\mathrm{Hz}$. Some melodies contained repeating notes. The particular renditions (when instrument and octave were considered) of the melodies were different on all melody trials of the experiment. Testing and training melodies were similarly constructed. There were $\mathbf{4 5}$ different melodies and renditions used on training trials, 15 on same trials, and $\mathbf{3 0}$ on different trials. There were 60 different melodies and renditions used on melody-test trials, plus the transposition changes according to the transposition test.

For transposition tests (SAME-TUNE DIFF-FREQ), melodies were transposed as little as four semitones to as many as $\mathbf{4 0}$ semitones. The following sequence specifies distance (in semitones), transposition direction $(+1-$ for higher/lower frequency changes, respectively), and testing order of transposition tests: $+32,+38,+40,+28,-9,-5,-27,-21$, $-19,-6,+10,+30,-10,+4,+9,-31,-6,+22,+9,-11,-8,-23$, $-19,-15,+40,-22,-32,-13$. It should be noted that there were no 12 -semitone (octave) transpositions.

For the other tests (DIFF-TUNE SAME-FREQ), both melodies on each trial shared the same notes. The second melody was a scrambled version of the first. By chance, some melody pairs began or ended on the same note. No pair had both melodies beginning and ending on the same note.

\section{Results and Discussion}

The results are shown in Figure 2. Training-trial performance is shown on the left. Performance was comparatively accurate with natural sounds $(\mathrm{BW}=75.5 \%, 76.5 \% ; \mathrm{FD}=76.9 \%, 78.4 \%$ for DIFF \& SAME, respectively) and somewhat less accurate with training melodies $(\mathrm{BW}=80.0 \%, 73.3 \%$; $\mathrm{FD}=53.3 \%, 66.7 \%$ for DIFF \& SAME, respectively).

Performance on the test trials is displayed as percent response. This is the response (same-different) that would be expected if the monkeys were matching melodies irrespective of frequency. Thus, for the DIFF-TUNE SAME-FREQ test, the percent different

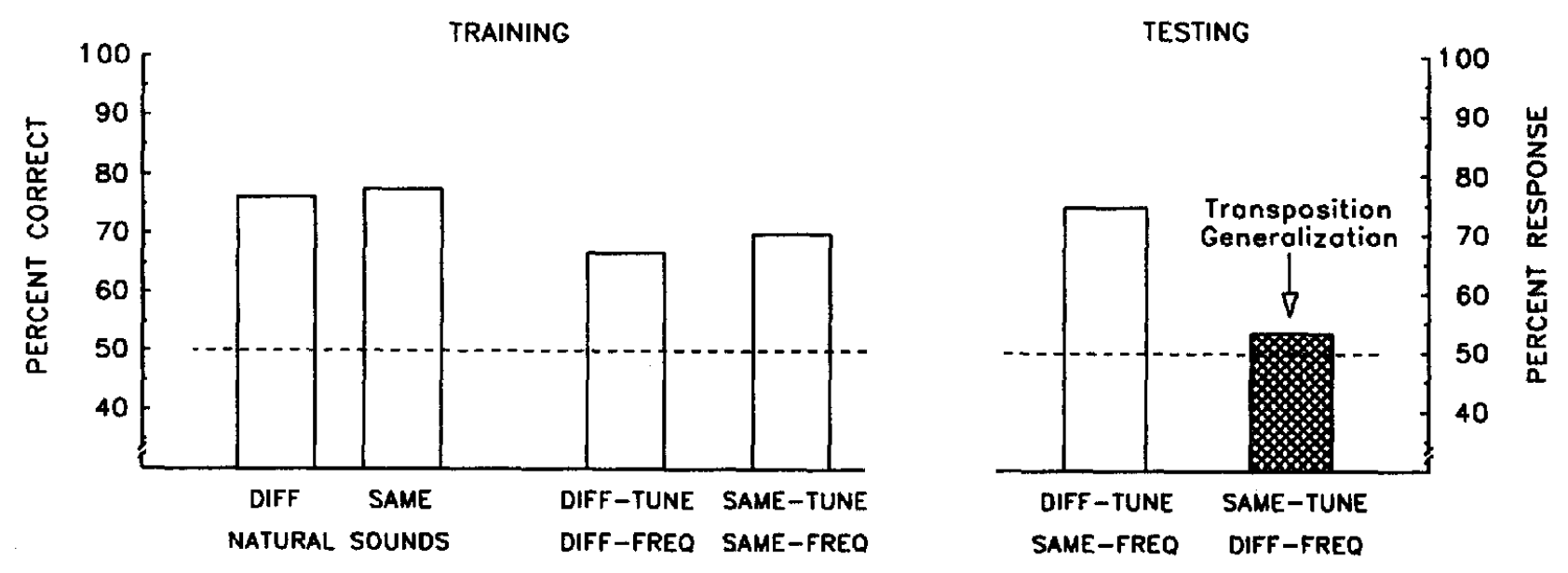

Figure 2. Mean sameldifferent (DIFF) training and testing performance of two monkeys with trials composed of natural/environmental sounds (left) and random-synthetic melodies (right). For DIFF-TUNE SAME-FREQ (frequency) testing trials, the percent different responses is plotted because the two melodies of a trial were different. For SAME-TUNE DIFF-FREQ testing trials, the percent same response is plotted because the two melodies of each trial were the same, even though their note frequencies were different. The dashed line is chance ( $50 \%$ correct) performance. 
(DIFF) response is plotted because the two melodies were different even though their notes were the same. These melodies were judged to be different $74 \%$ of the time $(73.3 \%$ for $\mathrm{BW}$ and $75.9 \%$ for FD) even though they shared the same six notes. This result shows that the monkeys were not under stimulus control of individual notes, which adds to the evidence that their responses were based on the relationship among notes, the melody.

For transposition tests (SAME-TUNE, DIFF-FREQ), percent same response was plotted because the melodies were the same even though the frequencies (FREQ) of the notes were different. These are the critical transposition tests, and therefore this histogram is filled in the figure. The monkeys did not generalize to these transposed melodies ( $46.7 \%$ for $\mathrm{BW}, 60 \%$ for FD). They judged them to be the same melody only $53.3 \%$ of the time. This performance was not (significantly) different from (50\%) chance- $t(1)=0.35, p>.5$, single means test: Hays, 1963, p. 311 -and was (significantly) different from training-trial (SAME and DIFF) performance, $F(1,4)=31.7, p<.01$. In conclusion, there is no evidence that these monkeys generalized to these transposed synthetic melodies.

\section{Experiment 2}

The lack of generalization to transposed melodies in Experiment 1 was puzzling. One possibility was that monkeys do not have this ability, as D'Amato (1988) had concluded. Another possibility was that the synthetic melodies were inadequate in some way for testing octave generalization. Their random composition did not result in what most listeners would refer to as a melodic tune. Indeed, $44 \%$ of these synthetic melodies had notes outside the appropriate diatonic scale, similar to what Trehub (1993) and Trehub, Thorpe, and Trainor (1990) referred to as "bad" melodies. Tunes that are not musical tend to be less memorable (e.g., Frances, 1958, Experiment 9; Krumhansl, 1979, Experiment 3; Trehub, Cohen, Thorpe, \& Morrongiello, 1986). Any detriment to the memorability of a melody would, in tum, be expected to adversely affect transposition. How could a transposed melody be matched to one previously heard, if the previous one cannot be remembered?

In Experiment 2, we explored transpositions of melodies that would be expected to be more musical, more scalar, more tonal, and more memorable than the synthetic melodies of Experiment 1. The rationale was that by maximizing these qualities we might maximize the chances of finding same-melody recognition in these monkeys. Among melodies considered to be most musical are childhood songs, such as "Old MacDonald," "Yankee Doodle," and "Happy Birthday" (e.g., Dowling, 1988; Kaliman \& Massaro, 1979; Unyk, Trehub, Trainor, \& Schellenberg, 1992). Most people find such childhood songs memorable, occasionally to the point of annoyance. In addition, (whole) octave transpositions were tested rather than partial octave transpositions. The rationale was that these two factors, childhood songs and octave transpositions, might work together to increase the chances of finding octave generalization and melody recognition in monkeys.

\section{Method}

\section{Subjects and Apparatus}

The subjects and apparatus were identical to Experiment 1.

\section{Procedure and Stimuli}

The procedure was similar to Experiment 1, except that childhood songs were tested. These childhood songs were the first six notes of "Row Row Row Your Boat," "Oh Susanna," "London Bridge," "Old MacDonald," "Yankee Doodle," "Ring Around the Rosey," "Skip To My Lou," "Two Bits," "Camptown Races," "Happy Birthday," and "How Much Is That Doggie In The Window." For one melody, "Skip To My Lou II," the last six notes were used. They were played in their original rhythms by a musician on a Yamaha DX7 electronic keyboard with the same instruments as in Experiment 1: Flute, Accordion, Spanish Guitar, Oboe, Electric Piano, Bag Pipe, Clarinet, Grand Piano, Honky-Tonk Piano, and Glockenspiel. Melodies were recorded in three different octaves spanning a frequency range of $131 \mathrm{~Hz}$ to $988 \mathrm{~Hz}$. There were 12 melodies, 10 instruments, and three octaves for a total of 360 recordings. Test melodies were novel renditions when instrument and octave were taken into account. Selection was quasirandom and as many aspects as possible were counterbalanced within the limits of the experiment.

Training trials were similar to Experiment 1. The natural-sound stimuli were selected quasirandomly from the same 520 stimulus pool used in Experiment 1. The synthetic melodies used in training were the same as Experiment 1, except that the order of first versus second melody on different trials varied quasirandomly. Each training melody was unique to a particular trial during the entire experiment. The sequence of trials was different from Experiment 1.

On two test trials, octave transpositions of two melodies (childhood song) were tested. On each of these test trials, there was an octave difference in frequency between presentations of a melody. Thus, these trials are referred to as Same-Melody, Different-Frequency (SAME-TUNE DIFF-OCTAVE). These were the octave-generalization test trials and were the trials of primary interest in this experiment. Within each test trial, both presentations of the childhood song were played by the same instrument. Selection of song, instrument, octave, and transposition direction (higher vs. lower frequency) was quasirandom.

On the remaining two test trials, two different melodies (childhood songs) were presented from the same frequency range or octave. Thus, these trials are referred to as Different-Melody, Same-Frequency trials (DIFF-TUNE SAME-FREQ) and are essentially tests for control by frequency (as opposed to melody). Like the octave-generalization test trials, both melodies were played by the same instrument and selection of song, instrument, and octave to be tested was quasirandom.

Reward on test trials was given for either response. Reward probability was set equal to training-trial accuracy from the previous session for each subject. This change in reinforcement probability was made so that test trials would be unlikely to be distinctive from training trials on the basis of outcome.

\section{Results and Discussion}

The results are shown in Figure 3. Training-trial performance is shown on the left. Training-trial accuracy was reasonably good with natural sounds $(\mathrm{BW}=78.7 \%, 78.2 \%$; $\mathrm{FD}=75.3 \%, 79.6 \%$ for DIFF \& SAME, respectively) and with synthetic melodies $(\mathrm{BW}=80.0 \%, 86.6 \% ; \mathrm{FD}=86.7 \%, 86.7 \%$ for DIFF \& SAME, respectively).

The most striking result was the substantial generalization to octave-transposed childhood songs, compared with the lack of any generalization to transposed synthetic melodies of Experiment 1. Octave generalization was $76.7 \%$ (for both monkeys) and is significantly different from chance performance, $t(1)>100, p<$ .0001 .

An analysis of variance (ANOVA) showed significant effects across training and testing conditions, $F(5,6)=6.90, p<.02$. 

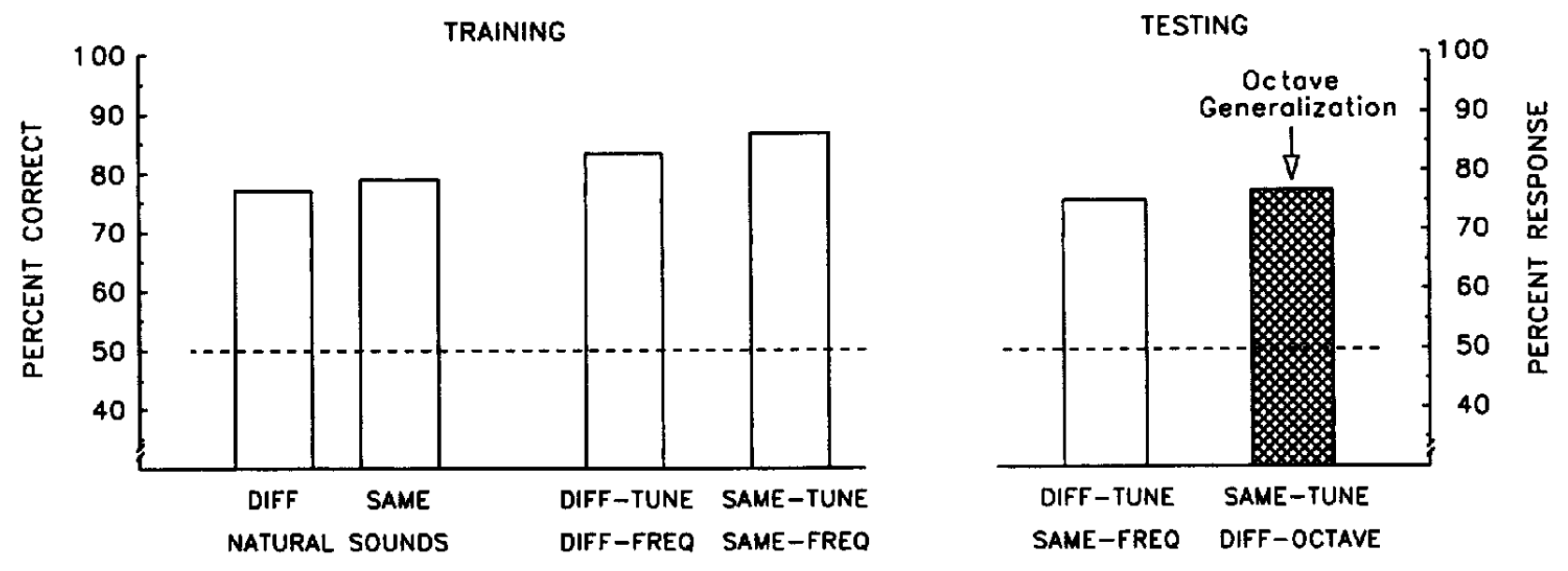

Figure 3. Mean training and testing performance of two monkeys with natural/environmental sounds and childhood songs such as "Happy Birthday." For DIFF-TUNE SAME-FREQ (DIFF = different; FREQ = frequency) testing trials, the percent different responses is plotted because the two songs were different. For SAME-TUNE DIFF-OCTAVE testing trials, the percent same response is plotted because the two melodies of each trial were the same song but the frequencies of their notes differed by an octave (factor of two). The dashed line is chance $(50 \%$ correct) performance.

Planned comparison tests (Sokal \& Rohlf, 1969, p. 234) using the $M S E$ (mean square error/residual) term from the ANOVA showed that octave generalization was not significantly different from training performance with natural sounds, $t_{s}(6)=0.05,0.38, p>$ .5 , for DIFF \& SAME, respectively. Thus, it can be said that generalization was complete because it was equivalent to trainingtrial performance.

This is the first definitive evidence (in our assessment) for octave generalization from a (nonhuman) animal species and the first evidence from a task where animals were required to compare pairs of musical passages. The generalization with childhood songs is interesting from a human developmental perspective. It might be reasonable to assume that human recognition of such octave transposed childhood songs would depend on a lifetime of exposure to these melodies (cf. Dowling, 1978). However, the monkeys showed good generalization to (octave) transposed childhood songs with little or no experience with them, let alone a lifetime of experience. The much greater generalization to childhood songs than synthetic melodies means that the critical difference is to be found in the melodies themselves.

Before considering manipulations that might affect octave generalization, it should be pointed out that there was some improvement on training trials with synthetic melodies relative to Experiment 1 . This slight improvement could have been due to the greater experience with the musical passages. The next experiment was conducted to evaluate any effect this greater experience might have on generalization to the transposed synthetic melodies of Experiment 1.

\section{Experiment 3}

We conducted Experiment 3 to test the possibility that greater experience with music stimuli might have influenced the difference in generalization between Experiments 1 and 2. Thus, Experiment 3 was essentially the third "leg" of an A-B-A experi- mental design, where the first test (A) is repeated to control for the possibility that experience has influenced the results. Synthetic melodies of Experiment 1 were retested with some minor modifications to make Experiment 3 more similar to Experiment 2 than was Experiment 1.

\section{Method}

\section{Subjects and Apparatus}

The subjects and apparatus were the same as in Experiments 1 and 2.

\section{Procedure}

Trials and stimuli in this experiment were similar to Experiment 1, except for a reduction in the total number of melodies to be tested on transposition tests. Training trials and training stimuli were similar in terms of stimulus sets and composition. Pairings (natural sounds), melody order on melody training, and trial sequences varied daily and were different than those of previous experiments.

On transposition tests, 12 of the $\mathbf{3 0}$ synthetic melodies tested in Experiment 1 were retested in this experiment. The 12 melodies were matched in terms of note repetitions to the 12 childhood songs of Experiment 2 . Thus, six melodies contained three different notes (plus three repetitions), five melodies contained four different notes, and one melody contained five different notes. These 12 melodies were recorded by the same 10 instruments and were tested at the same transpositions as in Experiment 1. The selection of instruments used to play the test melodies varied quasirandomly. When instrument and octave are considered, these renditions of the melodies had not been previously heard by the monkeys. The number of semitones transposed, direction of transposition, and the order of testing for the first block of the 12 melodies was $11,40,-32,9,-19,-9,-19$, $-13,32,28,-23,10$. Other randomized blocks of these same melodies and same transpositions (but different synthetic instruments) were also tested. As in Experiment 2, the reinforcement probability for either response on test trials was equal to the reinforcement rate from the previous session. The same number of test sessions (15), training trials, and testing trials ( 2 per session) were conducted. 


\section{Results}

The results are shown in Figure 4. As in Experiment 1, training trial accuracy with synthetic melodies was somewhat less accurate $(\mathrm{BW}=66.7 \%, 73.3 \%$; FD $=60.0 \%, 73.3 \%$ for DIFF \& SAME, respectively) than with natural sounds $(B W=81.2 \%, 82.8 \%$; FD $=82.0 \%, 84.6 \%$ for DIFF \& SAME, respectively).

Once again, the most important result was the lack of generalization $(51.7 \%)$ to transposed melodies $(60.0 \%$ for $\mathrm{BW}, 43.3 \%$ for FD), which was not significantly different from chance performance, $t(1)=0.19, p>.5$, single means test.

An ANOVA showed significant effect across training and testing conditions, $F(5,6)=8.75, p=.011$. Planned comparison tests (using the $M S E$ from the ANOVA) showed that generalization to transposed melodies differed significantly from training performance with natural sounds, $t_{\mathrm{s}}(6)=5.02,5.37, p>.01$, for DIFF \& SAME, respectively.

Experiment 3 essentially replicated Experiment 1 but with a smaller set of 12 synthetic melodies matched in terms of note repetitions to the childhood songs of Experiment 2. The lack of generalization to the transposed melodies was essentially similar (51.7\% vs. $53.4 \%$ from Experiment 1) and contrasts with the considerable generalization (76.7\%) to transposed childhood songs of Experiment 2. Thus, this experiment establishes that generalization to the childhood songs was not due to greater experience on the part of the monkeys.

\section{Experiment 4}

Experiment 3 retested the synthetic melodies tested in Experiment 1 but with the number of melodies, note repetitions, and reinforcement contingencies of Experiment 2. There were, however, three remaining differences other than the melodies themselves (childhood songs vs. synthetic melodies). A minor difference was the frequency range. The synthetic melodies covered a four-octave range, whereas the childhood songs covered only three octaves, the lower three octaves of the synthetic melodies. Another difference was the larger transposition distance for some synthetic melodies. Three synthetic melodies were transposed more than two octaves and one more than three octaves. A third difference was the partial octave transpositions of the synthetic melodies. Partial octave transpositions change the key (chroma) of the melody. These differences, particularly the latter two, could have influenced the lack of generalization to transposed synthetic melodies and thus were tested in Experiment 4.

The purpose of Experiment 4 was to test the same synthetic melodies of Experiment 3 but with one octave (12 semitone) transpositions and the same three octave range as used with the childhood songs.

\section{Method}

\section{Subjects and Apparatus}

The subjects and apparatus were the same as in previous experiments.

\section{Procedure}

Training trials and training stimuli in this experiment were similar to those of previous experiments. But the sequences, environmental-stimulus pairings, and order of presentation varied quasirandomly and were different from previous experiments. As in previous experiments, sessions contained 26 training trials and four testing trials, and the experiment was conducted for 15 sessions.

Transposition tests were octave-generalization tests (SAME-TUNE DIFF-OCTAVE). The same 12 synthetic melodies tested in Experiment 3 were tested with one-octave transpositions. The 12 synthetic melodies were recorded with the same 10 instruments, over the same three octave range as the childhood songs in Experiment 2. They were tested in randomized blocks of the 12 melodies with direction of transposition, particular octave, and instrument counterbalanced within the limits of the experiment. With instrument and octave taken into account, the renditions tested in this experiment were novel.

Melodies on control tests (DIFF-TUNE SAME-FREQ) were also novel renditions. These tests were similar to those of Experiment 2. The two different melodies presented on a trial shared the same frequency range and were recorded with the same instrument. Reward was given for either response on test trials with reward probability equivalent to the accuracy on training trials from the previous session for each subject.
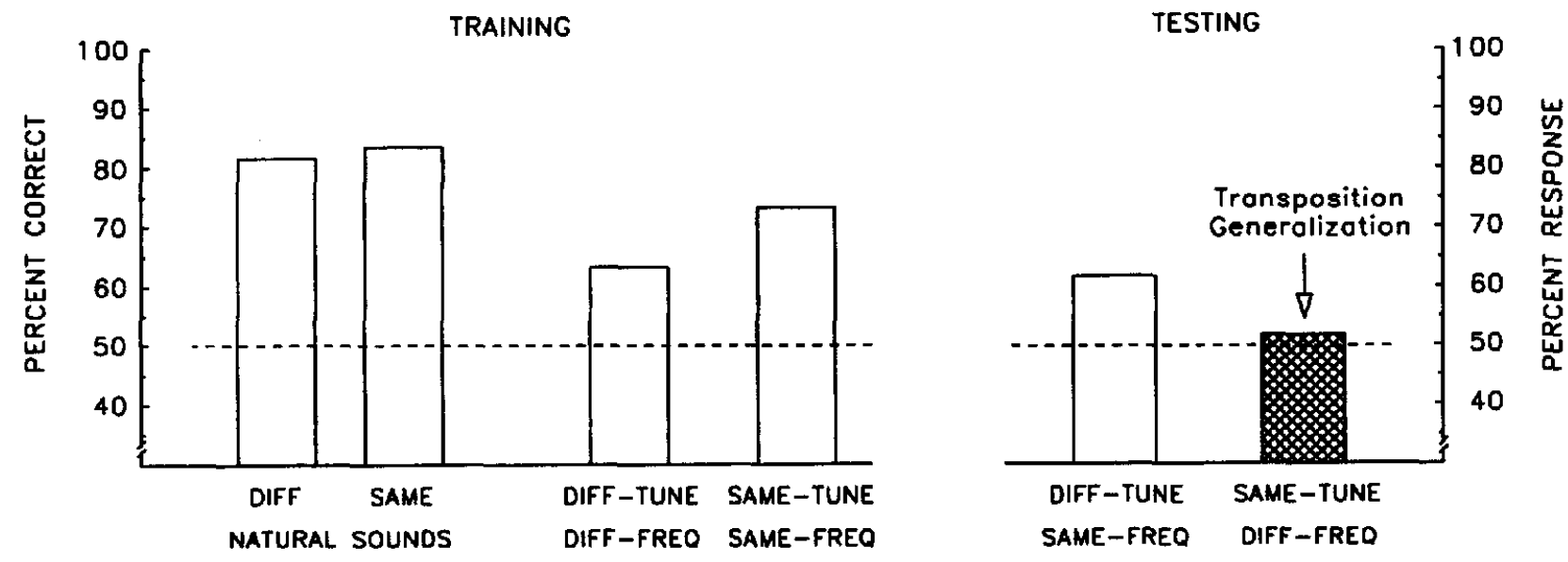

Figure 4. Results of a replication of Experiment 1 (Figure 2). Mean same/different (DIFF) training and testing performance of two monkeys with trials composed of natural/environmental sounds (left) and random-synthetic melodies (right). FREQ = frequency. 


\section{Results}

The results are shown in Figure 5 and are similar to those of Experiments 1 and 3. Training trial accuracy was good with natural sounds $(\mathrm{BW}=84.4 \%, 82.8 \%$; $\mathrm{FD}=84.4 \%, 84.9 \%$ for DIFF $\&$ SAME, respectively) and with synthetic melodies (BW $=86.7 \%$, 80.0\%; FD $=93.3 \%, 60.0 \%$ for DIFF \& SAME, respectively).

As in previous tests with synthetic melodies, the most important result was the lack of generalization $(51.7 \%)$ to one-octave transposed melodies ( $46.7 \%$ for $\mathrm{BW}, 56.7 \%$ for FD), which was not significantly different from chance performance, $t(1)=0.34, p>$ .5 , single means test.

An ANOVA showed significant effect of training and testing conditions, $F(5,6)=8.41, p=.012$. Planned comparison tests (using the ANOVA MSE term) showed significant differences for one-octave transpositions of synthetic melodies relative to naturalsound performances- $t_{\mathrm{s}}(6)=4.84,5.76, p<.01$, for SAME and DIFF, respectively-and relative to training-melody performances, $t_{\mathrm{s}}(6)=2.71,5.67, p<.05$, for DIFF \& SAME, respectively.

These results are comparable to the lack of generalization to transposed synthetic melodies from Experiment 1 (53.4\%) and Experiment $3(51.7 \%)$ and contrast with the octave generalization for childhood songs from Experiment 2 (76.7\%).

The results from this experiment together with those from previous experiments show a considerable difference in generalization to transposed synthetic melodies as opposed to childhood songs. The much greater generalization to childhood songs than synthetic melodies means that the critical difference lies in the structure of these melodies and songs. The last four experiments of this article focus on differences that might have led to octave generalization with childhood songs and not with synthetic melodies.

\section{Experiment 5}

If monkeys perceived childhood songs as we do, then the tendency to generalize these melodies might be subject to some of the same manipulations that affect our perception of melody. If generalization were a function of the transposition being exactly one octave, for example, then this generalization might diminish for partial-octave transpositions of the childhood songs. Whole octave transpositions preserve the key or chroma of the original melody and add to their similarity. This similarity is evident by notes of the same chroma in each octave being designated by the same letter name (e.g., C). Other transpositions change the key and reduce the number of shared notes, that is, notes sharing the same letter name. Transpositions of 5 or 7 semitones, for example, preserve 6 out of 7 notes of the scale. Such transpositions are equivalent to a change from $\mathrm{C}$ major to $\mathrm{F}$ or $\mathrm{G}$ major. By contrast, transpositions of 6 semitones (to the tritone) preserve only 2 of the original 7 notes. For example, the 7 notes of $C$ major C-D-E-FG-A-B become F\#-G\#-A\#-B-C\#-D\#-F. Such 6-semitone transpositions diminish the perception of same melody for humans (e.g., Krumhansl, Bharucha, \& Castellano, 1982; Massaro et al., 1980; Thompson \& Cuddy, 1992).

Experiment 5 tested half as well as whole octave transpositions of the childhood songs to determine whether or not such transpositions would diminish same-melody perception in monkeys as they do in humans. One-octave transpositions were retested to provide a within-test comparison and replication of the octavegeneralization test of Experiment 2. Tests were also conducted with two-octave transpositions. Two-octave transpositions fulfill all the conditions, requirements, and attributes of one-octave transpositions, but their greater pitch changes make them more extreme tests of octave generalization. If the monkeys respond different whenever there is any perceived difference, then there should be little octave generalization at two-octave transpositions. On the other hand, if they hear the transposed melody as the same melody and respond same to similar melodies, then there should be good octave generalization even to these two-octave transpositions. By testing two-octave transpositions, a second half-octave test (transposition to the tritone) was possible at 1.5 octaves. The same rationale that applied to 0.5 octave tests applies to 1.5 octave tests and provides another independent test at a more distant transposition. Thus, the purpose of Experiment 5 was to test monkeys with $0.5,1.0,1.5$, and 2.0 octave transpositions of the childhood songs tested in Experiment 2.
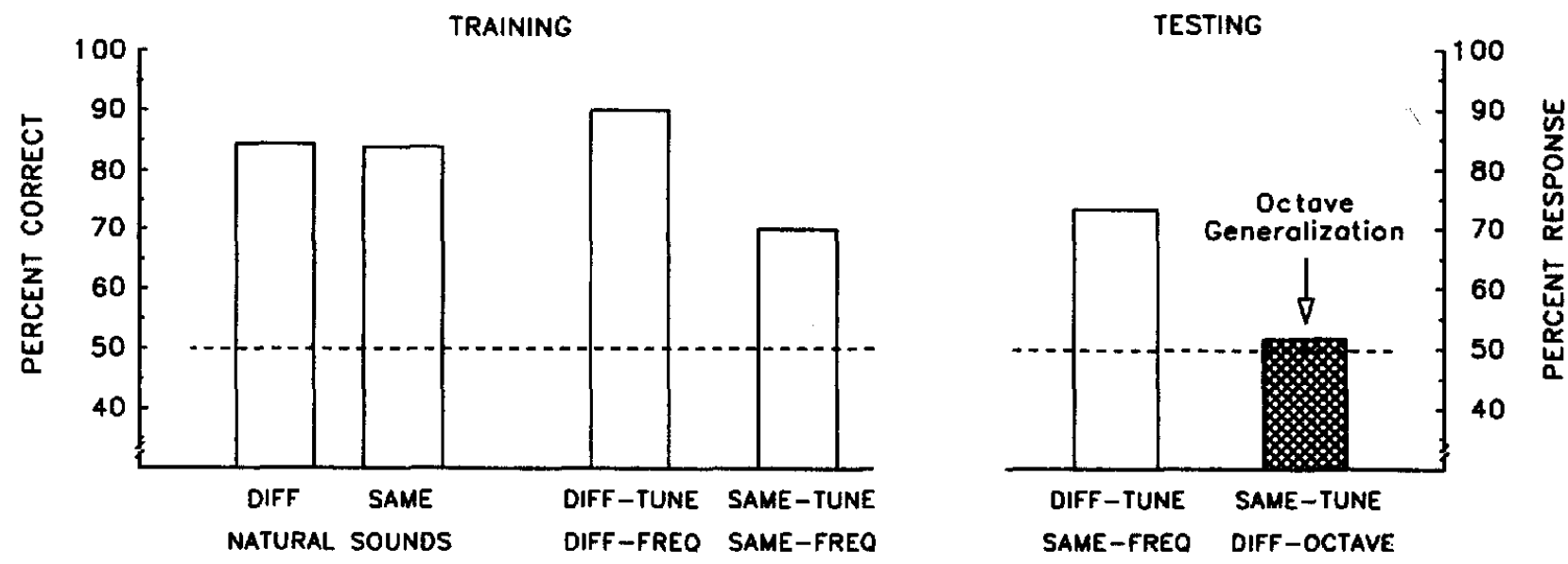

Figure 5. Results of a replication of Experiments 1 and 3 (Figures $2 \& 4$ ) with random-synthetic melodies tested with 1-octave transpositions. DIFF $=$ different; FREQ $=$ frequency. 


\section{Method}

\section{Subjects and Apparatus}

The subjects and apparatus were the same as in previous experiments.

\section{Procedure}

The procedure was similar to that of previous experiments, except that childhood songs were tested at transpositions of 0.5, 1.0, 1.5, and 2.0 octaves. There were 28 training trials each session, 26 natural-sound training trials and 2 melody-training trials. The melody-training trials were the same as in previous experiments so that difference in training regime would not introduce potential confounds when comparing experiments. Forty sessions were conducted in this experiment.

In each session, there were 2 melody-generalization test trials. The melodies, instruments, direction, and degree of transposition were different on these two test trials. On one of these trials, the transposition was a whole-octave ( 1.0 or 2.0 octaves) and on the other it was a partial-octave ( 0.5 or 1.5 octaves). Melodies within a trial were played by the same (synthetic) instrument. The variables of melody, instrument, and scale position (frequency) were varied quasirandomly and counterbalanced within the limits of the experiment.

The melodies were the same childhood songs as in Experiment 2. Each childhood song was recorded at five different frequencies within the three-octave range used in previous experiments, resulting in three full octave and two half octave renditions of each melody. They were recorded with the same 10 synthetic instruments used previously, yielding 600 different melodies and renditions (12 melodies $\times 10$ instruments $\times 5$ scale positions). The renditions tested, when considering the above three variables, were novel in this and other experiments of this article.

\section{Results and Discussion}

The results are shown in Figure 6. Training-trial performance is shown on the left. Training trial accuracy was good with natural sounds (BW $=83.7 \%, 80.7 \%$; FD $=80.8 \%, 81.5 \%$ for DIFF \& SAME, respectively) and with synthetic melodies (BW $=87.5 \%$, 90\%; FD $=87.5 \%, 82.5 \%$ for DIFF \& SAME, respectively).

Generalization to transposed melodies is shown in the filled histograms on the right of the figure. There was good generalization (77.5\%) to one-octave transpositions ( $80 \%$ for $\mathrm{BW}, 75 \%$ for FD), and this degree of generalization was similar to the oneoctave generalization (76.7\%) from Experiment 2. Generalization was even $10 \%$ better ( $87.5 \%$ ) to two-octave transpositions ( $90 \%$ for $\mathrm{BW}, \mathbf{8 5 \%}$ for $\mathrm{FD}$ ) and was even slightly better than trainingtrial accuracy.

ANOVA showed a significant effect across training and testing conditions, $F(7,8)=227.0, p<.0001$. Planned comparison tests (using the ANOVA MSE term) showed that the two-octave generalization was marginally better than the natural-sound training performance for SAME, $t_{s}(8)=2.55, p<.05$, but not for DIFF, $t_{s}(8)=1.98, p>.05$. The one-octave generalization was marginally worse than natural-sound training performance, $t_{s}(8)=2.97$, $2.40, p<.05$, for DIFF \& SAME, respectively.

By contrast, there was no significant generalization for either 0.5 -octave transpositions (35\% for BW, $40 \%$ for FD) or 1.5 octave transpositions ( $40 \%$ for BW, 35\% for FD). Planned comparison tests (using the ANOVA MSE term) showed that generalization with 0.5 or 1.5 octave transpositions differed significantly from natural-sound training performance, $t_{\mathrm{s}}(8)=22.8$, $22.2, p>.0001$, for DIFF \& SAME, respectively.

The substantial performance difference between full and half octave transpositions adds to the evidence that monkeys perceive these childhood songs similar to the way humans perceive them. The 0.5 and 1.5 transpositions preserved contour and interval of the melodies in the same manner as the 1.0 and 2.0 transpositions. Yet, there is no generalization to these half-octave transpositions. This means that monkeys use chroma of the scale in conjunction with other aspects such as melodic contour in making judgments of same melody, as do humans (Bartlett \& Dowling, 1980; Idson \& Massaro, 1978; Kallman \& Massaro, 1979; Krumhansl et al., 1982; Massaro et al., 1980; Thompson \& Cuddy, 1992).

Good octave generalization to two-octave transpositions was reassuring in light of extrapolations from human music perception and the large pitch changes produced by such transpositions. Such pitch changes are very noticeable for rhesus monkeys (e.g., Stebbins, 1973) as they are for humans (e.g., Stevens \& Volkmann, 1940).

\section{Experiment 6}

One purpose of Experiment 6 was to test transpositions of individual notes from the melodies in addition to the melodies
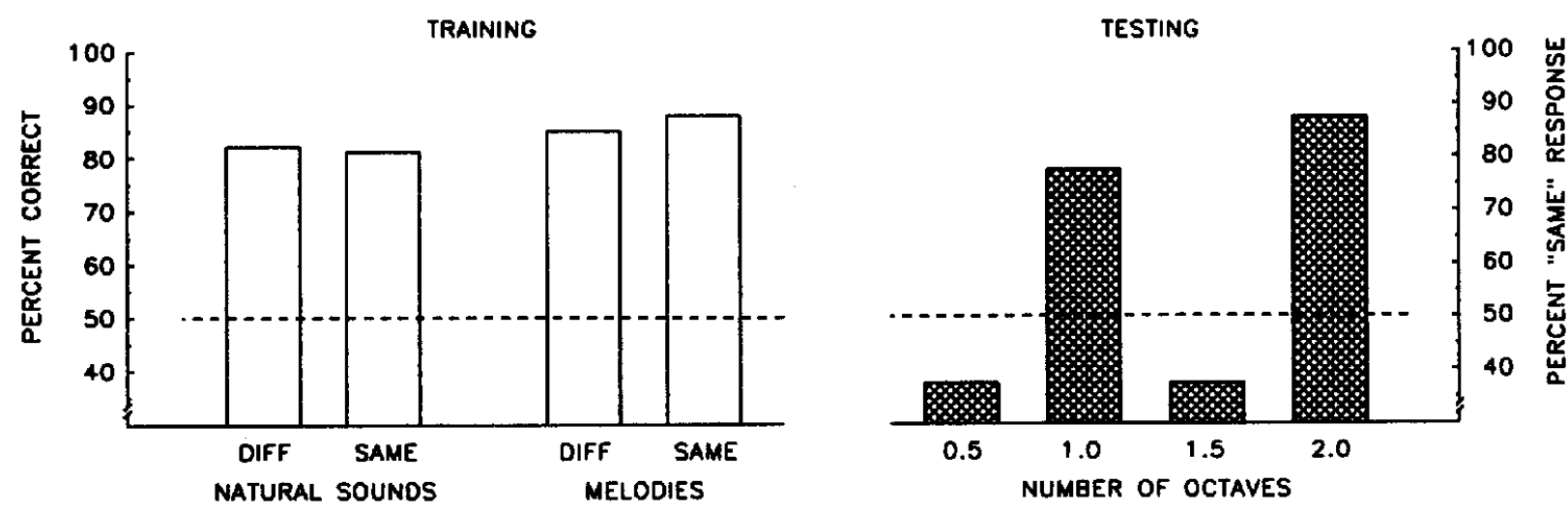

Figure 6. Training and testing performance with natural/environmental sounds and childhood songs such as "Happy Birthday." The childhood songs were tested at $0.5,1.0,1.5$, and 2.0 octaves of transposition. The 1.0 and 2.0 octave transpositions were tests of octave generalization. DIFF $=$ different. 
themselves. Notes were transposed and tested in Experiment 6 just like the melodies in the previous experiment. If the monkeys can discriminate these pitch changes (and report them accordingly), then such a result would show that pitch changes of melodies were discriminable despite the melodies being judged to be the same. Additionally, such a result would show that individual notes are inadequate for tests of octave generalization. It would show that melodies, and in particular musically strong melodies, are necessary for tests of octave generalization. The melody provides the musical context for octave generalization, and the melody is effectively removed when individual notes are tested. The transposition test of melodies (Experiment 5) was replicated in this experiment in a mixed design so that note (pitch) and melody generalizations could be compared within the same session.

\section{Method}

\section{Subjects and Apparatus}

The subjects and apparatus were the same as in previous experiments.

\section{Procedure}

The procedure was similar to that of Experiment 5, except that transpositions of individual notes were tested in addition to the whole melodies. Notes were tested in the same manner as the melodies. Because of the additional pitch-testing trials, there were no melody-training trials. There were 26 natural-sound training trials, two pitch-testing trials, and two melody-testing trials each session. For the two pitch-testing trials, notes were taken from the childhood songs and tested individually. The particular notes tested were not necessarily notes from the particular melodies tested in the same session. Selection of notes was quasirandom, counterbalanced for the melody from where they originated, position in the six-note melody, instrument, and octave within the limits of the experiment.

During sample (center speaker) presentations, notes were repeated to fill the 3-s sample listening time, like the melodies. Each note was presented

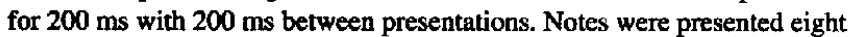
times during sample presentations and 5-15 times during test presentations (depending on when the choice response was made). Notes were tested at $0.5,1.0,1.5$, or 2.0 octave transpositions, as were melodies. The reinforcement probability for either choice response on all test trials was equivalent to the reinforcement rate on the previous session's training trials for each subject.
The two melody-testing (transposition) tests were similar to those of Experiment 5. The particular renditions of the childhood songs tested were novel (with respect to instrument and octave). Selection and counterbalancing of melodies was similar to the previous experiment.

\section{Results and Discussion}

The results from the experiment are shown in Figure 7. Accuracy on the natural-sound training trials remained high $(\mathrm{BW}=86.0 \%, 76.3 \% ; \mathrm{FD}=75.8 \%, 83.7 \%$ for DIFF \& SAME, respectively).

Test results for octave transposed melodies are shown in the right-hand portion of the figure. As in the previous experiment, there was good generalization (77.5\%) to 1-octave transpositions ( $85 \%$ for BW, $75 \%$ for FD) and even better generalization (85\%) to 2-octave transpositions ( $80 \%$ for $\mathrm{BW}, 90 \%$ for FD). Also like Experiment 5, there was no significant generalization (50\%) for 0.5 -octave transpositions (50\% for both monkeys) and no generalization (50\%) for 1.5-octave transpositions ( $45 \%$ for $\mathrm{BW}$, $55 \%$ for FD).

An ANOVA showed a significant effect across training and testing conditions, $F(9,10)=17.6, p<.001$. Planned comparison tests (using the ANOVA MSE term) showed no significant difference relative to natural-sound performance for 2-octave generalization- $t_{\mathrm{s}}(10)=0.9,0.7, p>.4$ - or 1-octave generalization, $t_{\mathrm{s}}(10)=0.16,0.0, p>.5$, for DIFF \& SAME, respectively. By contrast, comparisons showed significant differences relative to natural-sound performance for 1.5-octave generalization$t_{s}(10)=5.6,5.4, p<.001$-and for 0.5 -octave generalization, $t_{s}(10)=5.6,5.4, p<.001$, for DIFF \& SAME, respectively.

The test results from the pitch test with transposed notes are shown in the middle portion of Figure 7. Results from the pitch test show that with increasing distance (pitch) between the sample and test notes, the percentage of same responses decreased $(70 \%, 55 \%$, $45 \%, 45 \%$ for BW; $80 \%, 60 \%, 50 \%, 45 \%$ for FD). This is a monotonically decreasing similarity (increasing discrimination) effect. Comparisons to natural-sound training performances showed no significant difference at 0.5 -octave pitch transpositions, $t_{\mathrm{s}}(10)=1.1,0.9, p>.3$, for DIFF \& SAME, respectively. Other pitch transpositions were significantly $(p<.01)$ different from
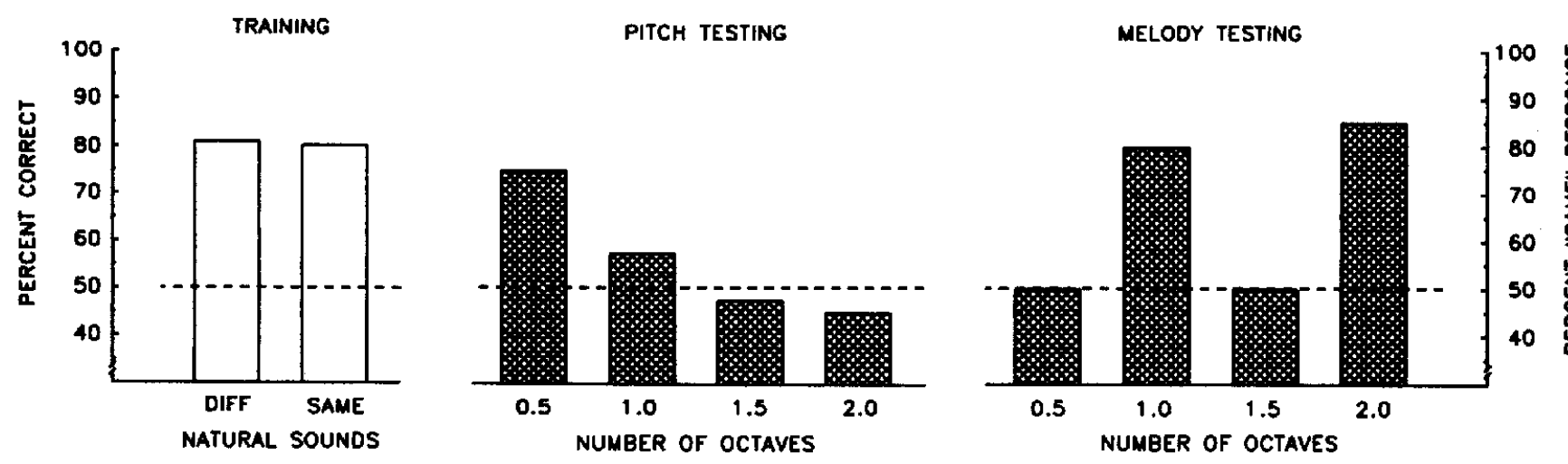

Figure 7. Training performance with natural/environmental sounds (left), testing performance with childhood songs (right), and testing performance for pitch of individual notes taken from the childhood songs (middle). The percent "SAME" response is the degree of generalization to childhood songs or notes transposed $0.5,1.0,1.5$, and 2.0 octaves. DIFF $=$ different. 
natural-sound training performances, $t_{\mathrm{s}}(10)=4.2,4.1$ for 1.0 octave; $t_{\mathrm{s}}(10)=6.1,5.9$ for 1.5 -octaves; $t_{\mathrm{s}}(10)=6.5,6.3$ for 2.0 octaves, for DIFF \& SAME, respectively.

The generalization trends were very different for childhood songs than for the individual notes from these songs. At transpositions of six semitones (i.e., to the tritone), melodies were not judged $(50 \%)$ to be the same. Paradoxically (relative to individual notes), increasing the distance, for example by doubling frequency, makes childhood songs more similar. Indeed, it makes them so similar that they are judged to be as similar as identical natural sounds. The trend goes through another inflection as the distance is further increased to 1.5 octaves. At 1.5 -octave separations (transpositions), the melody is judged to be the same only $50 \%$ of the time. There is another recapitulation with a further separation to two octaves. Childhood songs with note frequency differences as great as $1,110 \mathrm{~Hz}(370$ to $1,480 \mathrm{~Hz}$ for a two-octave transposition) are judged to be the same melody $85 \%$ of the time, even a slightly higher percentage than for one-octave transpositions or identical natural sounds.

These results highlight some differences between psychophysical discriminability and gestalt perception, and procedures that can influence octave generalization. One conclusion from this experiment is that notes, the subunits of a melody, do not result in octave generalization. This is a conclusion similar to the one based on octave transposition of notes with humans (e.g., Kallman, 1982) and raises additional concerns over studies claiming to show octave generalization to pure tones (e.g., Blackwell \& Schlosberg, 1943). From a gestalt standpoint, these same notes when presented as melodies configure to overshadow substantial pitch differences in the transpositions. Most interesting, on the basis of the evidence we have presented, is that not all melodies result in octave generalization. Only the childhood songs produced octave generalization, not the random-note synthetic melodies. It now remains to identify the properties of the melody that makes it a generalizable melody for rhesus monkeys. This is the topic of the last two experiments.

\section{Experiment 7}

The strong octave generalization for childhood songs of Experiments 2,5, and 6 contrasts with the lack of octave generalization for random synthetic melodies of Experiments 1, 3, and 4. The childhood songs were originally selected because they were thought to be musical and memorable by contrast to the synthetic melodies (cf. Trehub, 1993). Certainly one would not expect generalization of melodies that could not be remembered. Quantifying of musical tonality, however, is complicated. Two approaches may be relevant.

\section{Key Distance}

One index of tonality is key distance on a scale of the circle of fifths (e.g., Bartlett, 1993). Beginning with the note C, successive fifths (7 semitone steps) produces the series C, G, D, A, E, B, F\#, C\#, G\#, D\#, A\#, F, which is joined in a circle. Adjacent notes are structurally, musically, and tonally related for infants (Schellenberg \& Trehub, 1996) as well as adults (Bartlett, 1993; Takeuchi \& Hulse, 1992). Take, for example, a melody in the key of $\mathrm{C}$ major. The tonic, $\mathrm{C}$, forms a point of departure and arrival. The note, $G$, is a "perfect" fifth ( $3 / 2$ frequency ratio) above the tonic and is the secondary point of arrival. The perfect fifth above the note of $\mathrm{G}$ is D, and so on. Adjacent notes (e.g., C and G) are most strongly tonally related. Notes on opposite sides of the circle (e.g., $B$ and $F^{*}$ ) are least related. The childhood songs and synthetic melodies were analyzed for key distance with fewer steps (on the circle of fifths) indicating stronger tonality. The mean interval between notes (on the circle of fifths) was 2.71 steps for childhood songs and 3.06 steps for synthetic melodies. This difference, while not large, is in the same direction as the octave-generalization results. The smallest range (on the circle of fifths) is also related to tonality (Bartlett, 1993; Bartlett \& Dowling, 1988). The total range was 5.16 steps for childhood songs and 6.80 steps for synthetic melodies, which is also in the same direction as the octavegeneralization results. A more thorough evaluation of these circleof-fifths measures as they relate to octave generalization is presented in the General Discussion section.

\section{Maximum Key Profile Correlation (MKC)}

The ultimate goal of indexing tonality would seem to be an algorithm whereby musical passages could be varied along a continuum of tonality. At one extreme a melody would be atonal (like the random synthetic melodies) and at the other extreme a melody would be tonal (like the childhood songs). Takeuchi (1994) has supplied just such an algorithm. This algorithm uses human judgments of the stability of individual pitch classes in a tonal context of a particular key (Krumhansl \& Kessler, 1982). In the key of $\mathrm{C}$ major, for example, the perfect fifth, $\mathrm{G}$, as well as the tonic, $\mathrm{C}$, are judged highly stable and occur frequently. On the other hand, the tritone, $\mathrm{F}^{*}$, is judged unstable in $\mathrm{C}$ major and is therefore unlikely to occur. Krumhansl (1990) presents the list of stability ratings for scale values in the key of $\mathrm{C}$ major.

The Takeuchi MKC index is based on the evidence that the most stable pitch classes (i.e., the tonic, the perfect fifth, etc.) occur most often in the musical passage. The more frequently they occur, the more the key is established, and the more tonal is the musical passage. The MKC algorithm correlates the frequency of the 12 pitch classes (scale values) with the stability of the 24 possible major and minor key profiles. The largest correlation identifies the most likely key and indexes tonality.

The mean MKC tonality values for the childhood songs and the random-synthetic melodies of this article was 0.69 and 0.57 , respectively. This difference in tonality values is in the same direction as the difference in octave generalization for these melodies.

The MKC tonality algorithm can also be used to select the melodies to be tested. The purpose of Experiment 7 was to test melodies that were generated using the MKC tonality algorithm so that tonal and atonal melodies would be related on the same continuum. A secondary purpose of Experiment 7 was to evaluate the role of rhythm in octave generalization. Although rhythmic structure has little or no effect on human octave generalization (Massaro et al., 1980), rhythm and rhythm differences were present in the childhood songs. Therefore, the tonal and atonal melodies in Experiment 7 (and Experiment 8) were isochronous with notes and internote intervals of the same duration. 


\section{Method}

\section{Subjects and Apparatus}

The subjects and apparatus were the same as in previous experiments.

\section{Stimuli}

There were 24 tonal and 24 atonal melodies. Twelve of each type were used in training and the other 12 in testing. Each melody contained seven notes of $250 \mathrm{~ms}$ each. All melodies were recorded with the same keyboard instrument. The atonal melodies were selected so that they contained two or three pitch-contour changes and had MKC tonality values of less than 0.57 , resulting in a range of 0.57 to 0.32 . Although one cannot say that an atonal melody is truly in any key, the Krumhansl and Kessler (1982) key-finding algorithm does indicate the most likely key. The most likely key of the atonal melodies was identified to make tonal melodies from the atonal melodies. Certain notes were then modified, but the original contours of the melodies were preserved. In cases where the first or last notes were whole tones or semitones removed from the tonic, these notes were changed to the tonic. Tritones were changed to the perfect fifth. The resulting tonal melodies had MKC values of greater than 0.75 with a range of 0.75 to 0.93 . The melodies were from the three-octave range used previously.

\section{Procedure}

The training procedure was similar to that of previous experiments. There were 26 natural-stimulus training trials and one tonal and one atonal training trial per session. There were 12 different tonal and 12 different atonal melodies used in training. Melodies were presented once as sample from the center speaker and 1-3 times from side speakers, depending on when the choice response occurred. Same and different responses were rewarded according to whether the two stimuli (natural sounds or melodies) were identical or different, respectively.

There were two test trials each session. There were 12 different atonal and 12 different tonal melodies used in testing. Test melodies were different in contour from training melodies. Transpositions were one octave. The direction of transposition (to higher or lower frequencies) was different on the two test trials each session. Stimulus pairings and trial sequences varied daily and were counterbalanced within the limits of the experiment. The melodies were tested in two randomized blocks for a total of 24 sessions in the experiment.

On test trials, either response (sameldifferent) was rewarded with the reward probability equal to the subject's training-trial accuracy from the previous session.

\section{Results and Discussion}

The results are shown in Figure 8. Training-trial performance was slightly better for natural-sound stimuli $(B W=87.8 \%$, $85.5 \% ; \mathrm{FD}=89.1 \%, 85.9 \%$ for DIFF \& SAME, respectively) and tonal melodies $(\mathrm{BW}=91.7 \%, 91.7 \% ; \mathrm{FD}=100 \%, 75 \%$ for DIFF \& SAME, respectively) than for atonal melodies $(B W=75.0 \%$, $83.0 \%$; FD $=66.7 \%, 75.0 \%$ for DIFF \& SAME, respectively). The slightly less accurate performance with atonal melodies may have been due to the atonal melodies being less memorable than natural sounds or tonal melodies.

Test results for one-octave transpositions are shown in the right-hand portion of Figure 8. There was good generalization $(81.3 \%)$ to one-octave transposed tonal melodies $(83.3 \%$ for BW, $79.2 \%$ for FD). There was no significant generalization $(47.9 \%)$ to one-octave transposed atonal melodies $(50 \%$ for BW, $45.8 \%$ for FD).

An ANOVA showed a significant effect across training and testing conditions, $F(7,8)=12.9, p=.001$. Planned comparison tests (using the ANOVA MSE term) showed no significant difference of tonal melodies for 1-octave transpositions relative to natural-sound performance, $t_{\mathrm{s}}(8)=1.21,0.76, p>.2$, for DIFF \& SAME, respectively. Comparison tests showed significant differences for the atonal melodies relative to natural-sound performance, $t_{\mathrm{s}}(8)=7.1,6.6, p<.001$, for DIFF \& SAME, respectively.

Because octave generalization for tonal melodies was equivalent to training-trial performance, it can be concluded that octave shifts of tonal melodies result in melodies that are unchanged in this essential aspect from the original for rhesus monkeys. This good octave generalization rules out rhythm as an important variable in octave generalization with mesus monkeys, a result similar to a
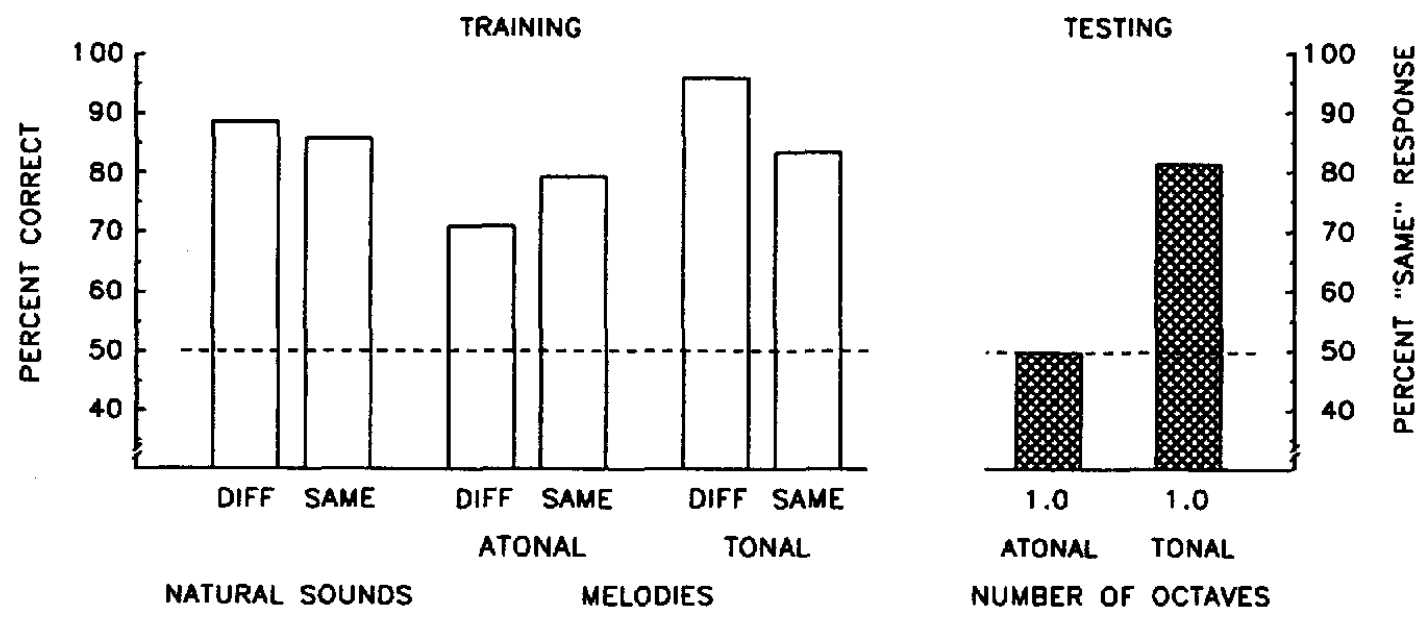

Figure 8. Training performance (left, unfilled histograms) with natural/environmental sounds, atonal melodies, and tonal melodies. Testing performance (right, filled histograms) with atonal and tonal melodies transposed an octave. $\mathrm{DIFF}=$ different. 
conclusion about human octave generalization (Massaro et al., 1980).

The lack of octave generalization for atonal melodies means that octave transpositions of these melodies destroys their perception of similarity. This result indicates that their good training-trial performance with atonal melodies may have depended on aspects of the musical passage other than the melody.

\section{Experiment 8}

Experiments 5 and 6 tested half-octave as well as whole-octave transpositions of childhood songs. The half-octave transpositions resulted in virtually no generalization. This is an interesting result from the standpoint of the role of chroma (key) in transpositions and octave generalization for rhesus monkeys. The tonal melodies provide an opportunity to replicate this result with melodies produced by the MKC tonality algorithm. Thus, Experiment 8 tested tonal and atonal melodies at half and full octave transpositions.

\section{Method}

\section{Subjects and Apparatus}

The subjects and apparatus were the same as in previous experiments.

\section{Procedure and Stimuli}

The procedure was similar to Experiment 7. Each session consisted of 26 natural-sound trials, one tonal and one atonal training trial, and one tonal and one atonal test trial. The octave separation on test trials was quasirandom with the restriction that one trial be a half octave and the other be a full octave. The melodies were the same as those tested in Experiment 7. Twelve tonal and atonal melodies were tested at half- and one-octave transpositions, and they covered the same three-octave range as the childhood songs. Direction (higher vs. lower frequencies) of the octave transposition was quasirandom and counterbalanced within each set of 12 melodies. Pairings of the sounds on training trials and the particular sequences of trials varied over the 24 test sessions of this experiment.

\section{Results and Discussion}

The results are shown in Figure 9. As in the previous experiment, training performance with atonal melodies was slightly less accurate $(\mathrm{BW}=83.3 \%, 58.3 \% ; \mathrm{FD}=75.0 \%, 83.3 \%$ for DIFF \& SAME, respectively) than with tonal melodies (BW $=83.3 \%$, 83.3\%; FD $=91.7 \%, 83.3 \%$ for DIFF \& SAME, respectively) or with natural sounds $(\mathrm{BW}=87.8 \%, 83.4 \% ; \mathrm{FD}=85.0 \%, 82.3 \%$ for DIFF \& SAME, respectively).

Also as in the previous experiment, there was good generalization $(79.2 \%)$ to one-octave transpositions of tonal melodies $(83.3 \%$ for BW, 75\% for FD). There was no significant generalization (45.8\%) to one-octave transpositions of atonal melodies $(41.7 \%$ for BW, 50\% for FD). As with childhood songs (Experiments $5 \&$ 6 ), there was a considerable decrease in generalization (62.5\%) for half-octave transpositions of the tonal melodies $(66.7 \%$ for BW, 58.3\% for FD). There was a similar decrease in generalization (33.3\%) for half-octave transpositions of atonal melodies $(25.0 \%$ for $\mathrm{BW}, 41.7 \%$ for $\mathrm{FD}$ ) and below-chance performance can be meaningfully interpreted in these tests.

An ANOVA showed a significant effect across training and testing conditions, $F(9,10)=10.8, p<.001$. Planned comparison tests (using the ANOVA MSE term) showed no significant difference $(p>3)$ for one-octave transpositions of tonal melodies relative to natural-sound performance- $t_{s}(10)=0.91,0.47$ for DIFF \& SAME, respectively-or tonal training melodies, $t_{s}(10)=0.5,0.0$ for DIFF \& SAME, respectively. Generalization for other transpositions were significantly $(p<.05)$ different from natural-sound training performances, $t_{\mathrm{s}}(10)=5.1,4.7$ for 0.5 octave tonal transpositions; $t_{\mathrm{s}}(10)=3.0,2.6$ for 1 -octave atonal transpositions; and $t_{\mathrm{s}}(10)=6.7,6.2$ for 0.5 -octave atonal transpositions for DIFF \& SAME performances, respectively.

As in Experiments 5 and 6, the melodic effect of generalization with full-octave transpositions of tonal melodies overrides any distance effect that would be expected on a simple prothetic (continuous gradation) continuum of generalization. Full-octave transpositions result in a greater distance change (frequency distance) but produce greater generalization than half-octave trans-
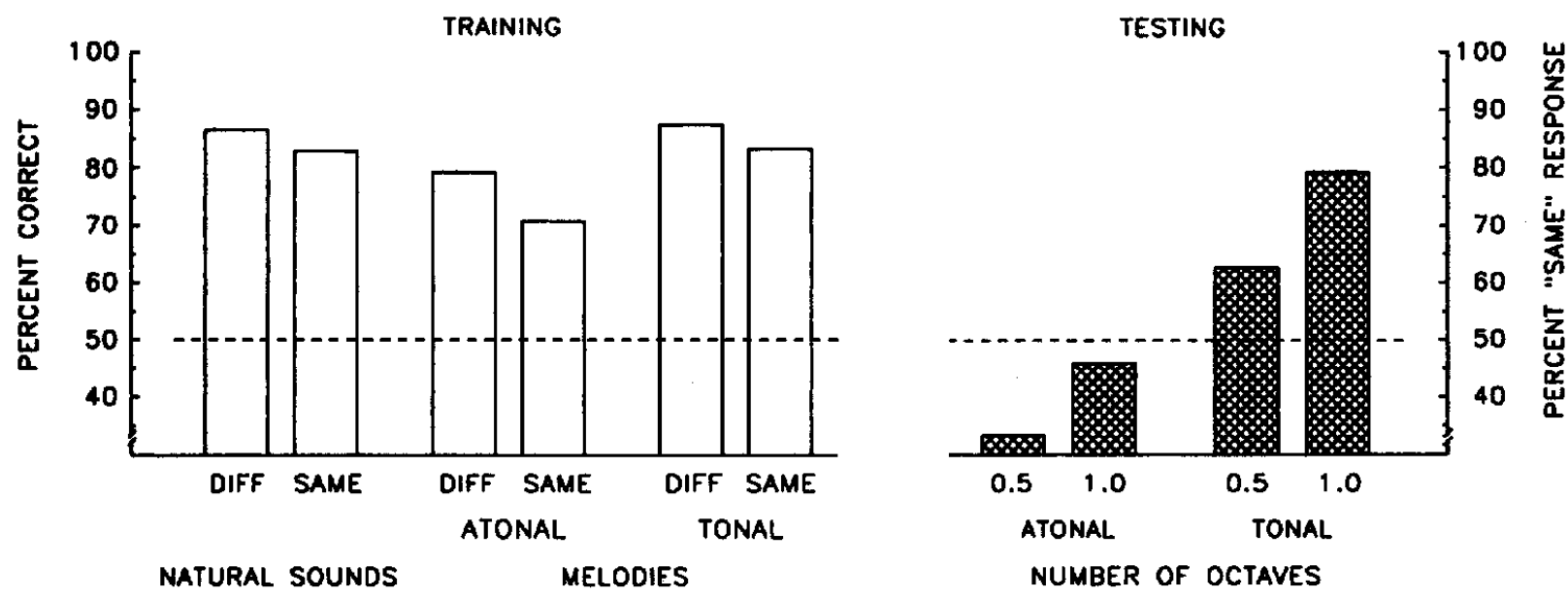

Figure 9. Training performance (left) with natural/environmental sounds, atonal melodies, and tonal melodies. Testing performance (right) with atonal and tonal melodies transposed 0.5 or 1.0 octaves. DIFF = different. 
positions. This result supports the argument that the controlling variable is the configural perception of notes into a melody, not the (specific) notes themselves.

\section{General Discussion}

We believe that the results from these experiments bear on several important issues that are presented in the following three sections.

\section{The Role of Tonality in Octave Generalization}

Rhesus monkeys showed octave generalization in five independent experiments (Experiments 2, 5, 6, 7, and 8). It can be said that there was complete octave generalization because octave generalization was equivalent to training-trial accuracy with natural sounds. These octave-generalization results, we believe, provide the first clear evidence of a nonhuman species perceiving musical passages in much the same way that humans perceive them. This evidence is further bolstered by results showing a lack of generalization to random synthetic melodies, atonal melodies, halfoctave transpositions, and single-note (pitch) transpositions. Halfoctave and 1.5-octave transposition tests of Experiments 5, 6, and 8 resulted in greatly reduced generalization relative to wholeoctave transpositions. This result is important because it shows that transpositions that do not preserve chroma degrade similarity of melodies for monkeys as they do for humans (Bartlett \& Dowling, 1980; Idson \& Massaro, 1978; Kallman \& Massaro, 1979; Krumhansl et al., 1982; Massaro et al., 1980; Thompson \& Cuddy, 1992).

\section{Gestalt Perception of Tonal Melodies}

The results from these eight experiments converge on the conclusion that musically strong tunes become a gestalt, a unit unto itself, for rhesus monkeys as they do for humans (e.g., Bartlett, 1993; Cuddy, 1993; Dowling, 1991). The melody can be transposed and moved on the frequency scale, with virtually undiminished recognition relative to the original, provided that the frequency change is some multiple or factor of two. Frequency doubling is a fundamental property of the stimuli (i.e., harmonics), the ear (i.e., basilar membrane), and music perception by primates (i.e., humans and thesus monkeys).

Nevertheless, octave generalization does not simply fall out of the frequency-doubling characteristics of the ear and the harmonics of the stimuli. If octave generalization were just the result of the physics of the ear and the stimuli, then there would have been just as good octave generalization for synthetic melodies, atonal melodies, and notes as there was for childhood songs and tonal melodies. The lack of (octave) generalization to synthetic melodies and atonal melodies (Experiments 1, 3, 4, 7, and 8) means that these tonally weak melodies are probably unmemorable to monkeys in much the same way that such tonally weak melodies are unmemorable for humans (cf. Cohen, 1982). The good trainingtrial performance with these tonally weak melodies may have been based on individual notes rather than the overall melody.

\section{Octave Generalization Does Not Occur for Individual Notes}

Even individual notes have harmonic and frequency doubling characteristics similar to the tonal melodies and childhood songs.
The pitch test with individual notes was important because instead of a melody degradation, individual notes eliminated the melody altogether. Testing individual notes is just like testing a "piece" of a melody with its melody (musical context) removed. Generalization for transposed notes was very different from generalization for childhood songs or tonal melodies. There was not the pattern of bimodal generalization to full octaves with an absence of generalization to the half octaves between. Instead, generalization for transposed notes was greatest for the half-octave transposition and declined with progressively greater transposition independent of half- or full-octave transpositions. This is a simple psychophysical distance effect (cf. Kallman, 1982; Stevens \& Volkmann, 1940).

\section{Tonality Measures and Correlations}

The difference between generalization to notes versus melodies underscores the unique role of the melody in octave generalization. A more precise relationship between the musical nature of the melodies and generalization can be made by correlating tonality measures with the degree of octave generalization. To this end, two circle-of-fifths measures and Takeuchi's MKC tonality measures for the different types of music were correlated with mean generalization for one-octave transpositions. These correlations are shown in Table 1. Correlations were computed for each individual subject using the one-octave generalization results from Experiments 2, 5, and 6 for childhood songs; Experiment 4 for synthetic melodies; and Experiments 7 and 8 for tonal and atonal melodies.

All three tonality measures of Table 1 showed strong correlations with octave generalization and were highly statistically significant. Pexhaps the most telling evaluation is the percentage of variance accounted for by each measure. The $77 \%$ and $72 \%$ of variance accounted by the two key-distance measures are substantial. The $94 \%$ of variance accounted for by the Takeuchi MKC algorithm is truly outstanding. It provides nearly a complete account of the octave-generalization results. Because the Takeuchi MKC tonality values are based on human judgments of how well different pitches fit into an established tonal context (Krumhansl \& Kessler, 1982), this near total account of the variance means that the monkey's perception of tonality is functionally very similar, if not identical, to that of humans.

Table 1

Octave Generalization, Tonality Coefficients, Key-Distance, and Range of Notes on Circle of Fifths for Different Melodies

\begin{tabular}{lcccc}
\hline & $\begin{array}{c}\text { Octave } \\
\text { Melody/song type }\end{array}$ & $\begin{array}{c}\text { Takeuchi's } \\
\text { generalization }\end{array}$ & \multicolumn{2}{c}{ Circle of fifths } \\
\cline { 5 - 6 } & tonality & Steps & Range \\
\hline Atonal & 46.9 & 0.447 & 3.68 & 9.70 \\
Synthetic & 51.7 & 0.572 & 3.06 & 6.80 \\
Childhood & 78.1 & 0.688 & 2.77 & 5.16 \\
Tonal & 80.3 & 0.848 & 2.86 & 6.25 \\
Correlation & & 0.97 & -0.88 & -0.85 \\
$F(1,14)$ & & $224.7^{*}$ & $47.5^{*}$ & $36.6^{*}$ \\
Percent of variance & & & & \\
$\quad$ accounted & & 94 & 77 & 72 \\
\hline
\end{tabular}

$*$ Statistically significant, $p<.0001$. 


\section{Implications for Species Similarity in the Perception of Tonality}

Such a functional similarity to humans warrants further comment. At a first glance, it might seem implausible that rhesus monkeys would respond to tonality in the same way that humans do. The tonal melodies were tonal according to one particular musical scale - the Western diatonic scale. Most of us have had a lifetime of experience with music that differs in tonality on the Western diatonic scale. The monkeys' experience with such music was limited by comparison. Why should monkeys be sensitive to tonality on the basis of a Western diatonic scale when there are many other musical scales on which tonality could vary, for example, the North Indian thāt or the Balinese sléndro or pélog scales? An answer may be provided by research with human listeners who are unfamiliar with these other scales. Krumhansl (1990) summarized a substantial body of literature and came to the conclusion that people are sensitive to tonal hierarchies of unfamiliar as well as familiar musical systems. For example, Western listeners were able to rate accurately the stability of pitches of North Indian music on the basis of thāt scale just as well as listeners with a lifetime of familiarity with this music (Castellano, Bharucha, \& Krumhansl, 1984). Similarly, Western as well as Balinese listeners were able to rate Balinese gamelan musical passages on the basis of the sléndro or pélog tuning systems in a manner that suggested strong tonal hierarchies (Kessler, Hansen, \& Shepard, 1984). Thus, although musical scales can vary substantially across cultures there is a commonality in the perception of tonality and tonal hierarchies. This same common perception of tonality appears to be also shared by rhesus monkeys.

Thus, the profound conclusion emerges that sensitivity to tonal hierarchies and the perception of tonality is not unique to humans. This trait is shown to be shared by thesus monkeys and may also be shared by some other species as well (e.g., monkeys, apes, avians, etc.). Furthermore, because sensitivity to tonal hierarchies is a relatively sophisticated musical ability, other principles of musical organization may also be shared.

\section{Critical Conditions in Testing Octave Generalization}

These conclusions regarding an animal's music perception awaited the development of adequate animal testing procedures. Humans can be asked, "Is this the same tune that you heard before?". Somehow we all know what the term "the same tune" means. It is another matter for animals to learn what "the same tune" means. There have been different approaches in training animals to identify "the same tune." One way to classify these approaches is in terms of whether they are relational tasks or absolute-identification tasks.

\section{The Problem: Absolute-Identification Tasks}

Absolute-identification tasks have the advantage in that they are comparatively easy tasks for animals to learn. Typically, one or more "tunes" are designated as $\mathbf{S}+$ (in which responses are rewarded) and others $S$ - (in which responses are not rewarded). These are typically labeled go/no-go tasks where S + means "go" or respond. Many animal species learn absolute-identification (go/ no-go) tasks in just a few weeks. By contrast, many months or even years are required for animals to learn a relational task such as a same-different task. Thus, for practical reasons absoluteidentification tasks are most often used.

Unfortunately, absolute-identification tasks have not been successful in testing melody perception and octave generalization. For example, in one absolute-identification task, monkeys were trained with one positive melody $(S+)$ and one negative melody $(S-)$. What was earlier thought to be octave generalization (D'Amato \& Salmon, 1982), was later found to depend on the presence or absence of certain individual notes (D'Amato, 1988; D'Amato \& Salmon, 1984). Even an increase from 1 to 3 in the number of $S+$ and $S$ - tunes did not alter the outcome. To learn the (absolute) identification of $\mathrm{S}+$, the tune must be heard hundreds, if not thousands, of times. Thus, control by the parts (e.g., notes) might override the whole (melody). It is apparent from the results presented in the present article that D'Amato's (1988) conclusion that monkeys cannot perceive tunes (music) was incorrect.

\section{The Solution: Relational Tasks and Many Stimuli}

The experiments of this article are relational tasks. In this case, the same-different task requires that the subject relate two musical passages. On same trials, the two musical passages were composed of the same notes. On octave-generalization trials, where the two musical passages also were judged to be the same, there were no common notes. Thus, the aspect that made these two musical passages sound the same was the melody. Because there were no common notes, it can be concluded that the melody transcended the particular notes used to play it.

A critical aspect of the experiments of this article was that the melody to be learned changed from trial to trial. This feature of changing melodies is made possible by relational learning. By continuously changing the melodies, minutia, and features (e.g., notes)—those absolute aspects of the stimuli-are less likely to gain control of behavior than if only a few melodies were used. With a large number of melodies, control is more likely to be established by the relationship between two melodies. Learning this relationship is what is meant by higher-order concept learning. It is higher order because the relationship or concept, samedifferent concept in this case, transcends the individual stimuli (natural sounds, musical passages) used in training and testing.

\section{A Musical Context}

Another critical aspect of this research was testing octave generalization in a musical context (cf. Kallman, 1982). As previously discussed, notes tested individually do not show octave generalization because the melody, or musical context, has been eliminated. The melody is the musical context and provides the basis for octave generalization.

\section{Some Implications for Nature-Nurture Issues in Music Perception}

It is not uncommon for music and language development to be considered closely related cognitive skills (e.g., Trehub \& Trainor, 1994). Proposals that music and language are closely related tend to reinforce the common belief that music and language set humans apart from other animal species. Debate often moves on to 
consider whether music abilities are inherited or learned with the implicit assumption that the music abilities being considered are unique to humans (e.g., Attneave \& Olson, 1971; Burns \& Ward, 1982; Dowling, 1978; Ward, 1970). The results presented in this article question the premise of this debate, and impact both nurture and nature arguments of music perception. Although the monkeys were exposed to music, their exposure was much less than that of most humans. Unlike humans, the monkeys probably never heard any of the childhood songs before being tested with them in these experiments. As to inherited aspects of music perception (the nature part), it is clear that we are not unique in our ability to perceive tunes and identify them irrespective of different notes. Rhesus monkeys apparently transduce, store, process, and relate musical passages much in the same way that we do. The matching of octave-transposed tunes depends on a memory system that stores higher-order representations of tunes. They are higher order because they transcend the original notes. It is the relationship among notes, the gestalt, that forms the essence of the melody or tune.

\section{References}

Attneave, F., \& Olson, R. K. (1971). Pitch as a medium: A new approach to psychological scaling. American Journal of Psychology, 84, 147-166.

Bartlett, J. C. (1993). Tonal structure of melodies. In T. J. Tighe \& W. J. Dowling (Eds.), Psychology and music (pp. 39-61). Hillsdale, NJ: Erlbaum.

Bartlett, J. C., \& Dowling, W. J. (1980). The recognition of transposed melodies: A key-distance effect in developmental perspective. Journal of Experimental Psychology: Human Perception \& Performance, 6, 501-515.

Bartlett, J. C., \& Dowling, W. J. (1988). Scale structure and similarity of melodies. Music Perception, 5, 285-314.

Blackwell, H. R., \& Schlosberg, H. (1943). Octave generalization, pitch discrimination, and loudness thresholds in the white rat. Joumal of Experimental Psychology, 33, 407-419.

Burns, E. M., \& Ward, W. D. (1982). Intervals, scales, and tuning. In D. Deutsch (Ed.), The psychology of music (pp. 241-270). New York: Academic Press.

Castellano, M. A., Bharucha, J. J., \& Krumhansl, C. L. (1984). Tonal hierarchies in the music of North India. Journal of Experimental Psychology: General, 113, 394-412.

Cohen, A. J. (1982). Exploring the sensitivity to structure in music. Canadian University Music Review, 3, 15-30.

Cuddy, L. L. (1993). Melody comprehension and tonal structure. In T. J. Tighe \& W. J. Dowling (Eds.), Psychology and music (pp. 19-38). Hillsdale, NJ: Erlbaum.

Cynx, J. (1993). Auditory frequency generalization and a failure to find octave generalization in a songbird, the European starling (Sturnus vulgaris). Journal of Comparative Psychology, 107, 140-146.

D'Amato, M. R. (1988). A search for tonal pattern perception in Cebus monkeys: Why monkeys can't hum a tune. Music Perception, 5, 453480.

D'Amato, M. R., \& Salmon, D. P. (1982). Tune discrimination in monkeys (Cebus apella) and in rats. Animal Learning \& Behavior, 10, 126-134.

D'Amato, M. R., \& Salmon, D. P. (1984). Processing of complex auditory stimuli (tunes) by rats and monkeys (Cebus apella). Animal Learning \& Behavior, 12, 184-194.

Demany, L., \& Armand, F. (1984). The perceptional reality of tone chroma in early infancy. Joumal of the Acoustical Society of America, 76, $57-66$.

Deutsch, D. (1972). Octave generalization and tune recognition. Perception \& Psychophysics, 11, 411-412.
Dooling, R. J., Brown, S. D., Park, T. J., Okanoya, D., \& Soli, S. D. (1987). Perceptual organization of acoustic stimuli by budgerigars (Melopsittacus undulatus). Journal of Comparative Psychology, 101, 139-149.

Dowling, W. J. (1978). Scale and contour: Two components of a theory of memory for melodies. Psychological Review, 85, 341-354.

Dowling, W. J. (1988). Tonal structure and children's early learning of music. In J. Sloboda (Ed.), Generative processes in music (pp. 113-128). Oxford, England: Clarendon.

Dowling, W. J. (1991). Tonal strength and melody recognition after short and long delays. Perception \& Psychophysics, 50, 305-313.

Dowling, W. J., \& Harwood, D. L. (1986). Music cognition. New York: Academic Press.

Dowling, W. J., \& Hollombe, A. W. (1977). The perception of melodies distorted by splitting into several octaves: Effects of increasing proximity and melodic contour. Perception \& Psychophysics, 21, 60-64.

Frances, R. (1958). La perception de la musique [The perception of music]. Paris: J. Vrin.

Gillan, D. J., Premack, D., \& Woodruff, G. (1981). Reasoning in the chimpanzee: I. Analogical reasoning. Joumal of Experimental Psychology: Animal Behavior Processes, 7, 1-17.

Hays, W. L. (1963). Statistics for psychologists. New York: Holt, Rinehart, \& Winston.

Homa, D., Cross, J., Comell, D., Goldman, D., \& Shwartz, S. (1973). Prototype abstraction and classification of new instances as a function of number of instances defining the prototype. Joumal of Experimental Psychology, 101, 116-122.

Homa, D., \& Vosburgh, R. (1976). Category breadth and the abstraction of prototypical information. Journal of Experimental Psychology: Human Learning \& Memory, 2, 322-330.

Hulse, S. H., \& Cynx, J. (1985). Relative pitch perception is constrained by absolute pitch in songbirds (Mimus, Molothus, and Stumus). Joumal of Comparative Psychology, 99, 176-196.

Hulse, S. H., \& Cynx, J. (1986). Interval and contour in serial pitch perception by a passerine bird, the European starling (Sturnus vulgaris). Journal of Comparative Psychology, 100, 215-228.

Idson, W. L., \& Massaro, D. W. (1978). A bidimensional model of pitch in the recognition of melodies. Perception \& Psychophysics, 24, 551-565.

Kallman, H. J. (1982). Octave equivalence as measured by similarity ratings. Perception \& Psychophysics, 32, 37-49.

Kallman, H. J., \& Massaro, D. W. (1979). Tone chroma is functional in melody recognition. Perception \& Psychophysics, 26, 32-36.

Kessler, E. J., Hansen, C., \& Shepard, R. N. (1984). Tonal schemata in the perception of music in Bali and the West. Music Perception, 2, 131-165.

Krumhansl, C. L. (1979). The psychological representation of musical pitch in a tonal context. Cognitive Psychology, 11, 346-374.

Krumhansl, C. L. (1990). Cognitive foundations of musical pitch. New York: Oxford University Press.

Krumhansl, C. L., Bharucha, J., \& Castellano, M. A. (1982). Key distance effects on perceived harmonic structure in music. Perception \& Psychophysics, 32, 96-108.

Krumhansl, C. L., \& Kessler, E. J. (1982). Tracing the dynamic changes in perceived tonal organization in spatial representation of musical keys. Psychological Review, 89, 334-368.

Massaro, D. W., Kallman, H. J., \& Kelly, J. L. (1980). The role of tone height, melodic contour, and tone chroma in melody recognition. Journal of Experimental Psychology: Human Learning and Memory, 6, 77-90.

Pick, A. D., \& Palmer, C. F. (1993). Development of the perception of musical events. In T. J. Tighe \& W. J. Dowling (Eds.), Psychology and music (pp. 197-213). Hillsdale, NJ: Erlbaum.

Premack, D. (1983a). Animal cognition. Annual Review of Psychology, 34, 351-362.

Premack, D. (1983b). The codes of man and beasts. The Behavioral and Brain Sciences, 6, 125-167. 
Ralston, J. V., Herman, L. M., Williams, N. S., Gory, J. D., \& Jerger, K. K. (1988). Melody recognition by an Atlantic bottlenosed dolphin. Joumal of the Acoustical Society of America (Suppl.), 77.

Richards, D. G., Wolz, J. P., \& Herman, L. M. (1984). Vocal mimicry of computer-generated sounds and vocal labeling of objects by a bottlenosed dolphin, Tursiops truncatus. Journal of Comparative Psychology, 98, 10-28.

Schellenberg, E. G., \& Trehub, S. E. (1996). Natural musical intervals: Evidence from infant listeners. Psychological Science, 7, 272-277.

Shepard, R. N. (1982). Structural representations of musical pitch. In D. Deutsch (Ed.), The psychology of music (pp. 344-390). New York: Academic Press.

Sokal, R. R., \& Rohlf, F. J. (1969). Biometry. San Francisco: Freeman.

Stebbins, W. C. (1973). Hearing of old world monkeys. American Joumal of Physical Anthropology, 38, 357-364.

Stevens, S. S., \& Volkmann, J. (1940). The relation of pitch to frequency: A revised scale. American Journal of Psychology, 53, 329-353.

Takeuchi, A. H. (1994). Maximum key-profile correlation (MKC) as a measure of tonal structure in music. Perception \& Psychophysics, 56, 335-346.

Takeuchi, A. H., \& Hulse, S. H. (1992). Key-distance effects in melody recognition reexamined. Music Perception, 10, 1-24.

Thompson, R. K. R. (1980). Auditory cued reversal and matching-tosample learning by thesus monkeys. Antropologia Contemporanea, 3, 284-292.

Thompson, W. F., \& Cuddy, L. L. (1992). Perceived key movement in four-voice harmony and single voices. Music Perception, 9, 427-438.

Trehub, S. E. (1993). The music listening skills of infants and young children. In T. J. Tighe \& W. J. Dowling (Eds.), Psychology and music (pp. 161-176). Hillsdale, NJ: Ertbaum.

Trehub, S. E., Cohen, A. J., Thorpe, L. A., \& Morrongiello, B. A. (1986). Development of the perception of musical relations: Semitone and diatonic structure. Journal of Experimental Psychology: Human Perception and Performance, 12, 295-301.
Trehub, S. E., Morrongiello, B. A., \& Thorpe, L. A. (1985). Children's perception of familiar melodies: The role of intervals, contour, and key. Psychomusicalogy, 5, 39-48.

Trehub, S. E., Thorpe, L. A., \& Trainor, L. J. (1990). Infants' perception of good and bad melodies. Psychomusicology, 9, 5-15.

Trehub, S. E., \& Trainor, L. J. (1994). Listening strategies in infancy: The roots of language and musical development. In S. McAdams \& E. Bigand (Eds.), Cognitive aspects of human audition (pp. 278-327). London: Oxford University Press.

Unyk, A. M., Trehub, S. E., Trainor, L. J., \& Schellenberg, E. G. (1992). Lullabies and simplicity: A cross-cultural perspective. Psychology of Music, 20, 15-28.

Ward, W. D. (1970). Musical perception. In J. V. Tobias (Ed.), Foundations of modern auditory theory (Vol. 1, pp. 405-447). New York: Acadernic Press.

Wright, A. A., Cook, R. G., \& Kendrick, D. F. (1989). Relational and absolute stimulus learning by monkeys in a memory task. Journal of the Experimental Analysis of Behavior, 52, 237-248.

Wright, A. A., Cook, R. G., Rivera, J. J., Sands, S. F., \& Delius, J. D. (1988). Concept learning by pigeons: Matching to sample with trialunique video picture stimuli. Animal Learning and Behavior, 16, 436444.

Wright, A. A., Santiago, H. C., Sands, S. F., \& Urcuioli, P. J. (1984). Pigeon and monkey serial probe recognition: Acquisition strategies and serial position effects. In H. L. Roitblat, T. Bever, \& H. S. Terrace (Eds.), Animal cognition (pp. 353-374). Hillsdale, NJ: Erlbaum.

Wright, A. A., Shyan, M. R., \& Jitsumori, M. (1990). Auditory samel different concept learning by monkeys. Animal Learning \& Behavior, 18, 287-294.

Received July 30, 1998

Revision received July 6, 1999

Accepted July 7, 1999

\section{Correction to Friedman and Brown (2000)}

The article "Reasoning About Geography," by Alinda Friedman and Norman R. Brown (Journal of Experimental Psychology: General, 2000, Vol. 129, No. 2, pp. 193-219), contained an error.

On page 211 , the Table 6 note incorrectly reads " $t(270)$ for all first estimates; $t(90)$ for second estimates with Lima as the seed fact; $1(81)$ for second estimates with Rio as the seed fact." The correct number of degrees of freedom for all tests is 29. 